\title{
Mitochondrial phylogeography and population structure of the cattle tick Rhipicephalus appendiculatus in the African Great Lakes region
}

\author{
Gaston S. Amzati ${ }^{1,2,3^{*}}$ (D), Roger Pelle ${ }^{3}$, Jean-Berckmans B. Muhigwa ${ }^{2}$, Esther G. Kanduma ${ }^{4}$, Appolinaire Djikeng ${ }^{3,5}$, \\ Maxime Madder ${ }^{6}$, Nathalie Kirschvink ${ }^{1}$ and Tanguy Marcotty ${ }^{1}$
}

\begin{abstract}
Background: The ixodid tick Rhipicephalus appendiculatus is the main vector of Theileria parva, wich causes the highly fatal cattle disease East Coast fever (ECF) in sub-Saharan Africa. Rhipicephalus appendiculatus populations differ in their ecology, diapause behaviour and vector competence. Thus, their expansion in new areas may change the genetic structure and consequently affect the vector-pathogen system and disease outcomes. In this study we investigated the genetic distribution of R. appendiculatus across agro-ecological zones (AEZs) in the African Great Lakes region to better understand the epidemiology of ECF and elucidate $R$. appendiculatus evolutionary history and biogeographical colonization in Africa.
\end{abstract}

Methods: Sequencing was performed on two mitochondrial genes (cox1 and 12S rRNA) of 218 ticks collected from cattle across six AEZs along an altitudinal gradient in the Democratic Republic of Congo, Rwanda, Burundi and Tanzania. Phylogenetic relationships between tick populations were determined and evolutionary population dynamics models were assessed by mismach distribution.

Results: Population genetic analysis yielded 22 cox 1 and 9125 haplotypes in a total of 209 and 126 nucleotide sequences, respectively. Phylogenetic algorithms grouped these haplotypes for both genes into two major clades (lineages A and B). We observed significant genetic variation segregating the two lineages and low structure among populations with high degree of migration. The observed high gene flow indicates population admixture between AEZs. However, reduced number of migrants was observed between lowlands and highlands. Mismatch analysis detected a signature of rapid demographic and range expansion of lineage A. The star-like pattern of isolated and published haplotypes indicates that the two lineages evolve independently and have been subjected to expansion across Africa.

(Continued on next page)

\footnotetext{
*Correspondence: gastonamzati@gmail.com

'Unit of Integrated Veterinary Research, Department of Veterinary Medicine,

Faculty of Sciences, Namur Research Institute for Life Sciences (NARILIS),

University of Namur (UNamur), Rue de Bruxelles 61, 5000 Namur, Belgium

${ }^{2}$ Research Unit of Veterinary Epidemiology and Biostatistics, Faculty of

Agricultural and Environmental Sciences, Université Evangélique en Afrique,

P.O. Box 3323, Bukavu, Democratic Republic of the Congo

Full list of author information is available at the end of the article
}

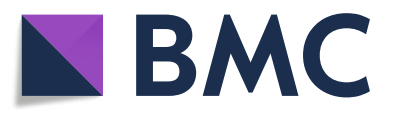

(c) The Author(s). 2018 Open Access This article is distributed under the terms of the Creative Commons Attribution 4.0 International License (http://creativecommons.org/licenses/by/4.0/), which permits unrestricted use, distribution, and reproduction in any medium, provided you give appropriate credit to the original author(s) and the source, provide a link to the Creative Commons license, and indicate if changes were made. The Creative Commons Public Domain Dedication waiver (http://creativecommons.org/publicdomain/zero/1.0/) applies to the data made available in this article, unless otherwise stated. 


\begin{abstract}
(Continued from previous page)
Conclusions: Two sympatric $R$. appendiculatus lineages occur in the Great Lakes region. Lineage A, the most diverse and ubiquitous, has experienced rapid population growth and range expansion in all AEZs probably through cattle movement, whereas lineage $B$, the less abundant, has probably established a founder population from recent colonization events and its occurrence decreases with altitude. These two lineages are sympatric in central and eastern Africa and allopatric in southern Africa. The observed colonization pattern may strongly affect the transmission system and may explain ECF endemic instability in the tick distribution fringes.
\end{abstract}

Keywords: East Coast fever, Theileria parva, Rhipicephalus appendiculatus, Phylogenetic, cox1, 125 rRNA, Ticks, Evolutionary history, Agro-ecological zones, Population genetics

\section{Background}

The ixodid brown ear tick Rhipicephalus appendiculatus is the main vector of the protozoan pathogen Theileria parva, the causative agent of a fatal lymphoproliferative cattle disease known as East Coast fever (ECF). East Coast fever is a highly pathogenic and the most economically important tick-borne disease of cattle in 12 sub-Saharan African countries, including Burundi, Democratic Republic of Congo and Rwanda [1]. Rhipicephalus appendiculatus is the most abundant tick in the Great Lakes region of Central Africa, where its burden and distribution vary significantly among agro-ecological zones (AEZs) [2-4]. The geographical dispersal pattern and population dynamics of this tick are mainly driven by climatic conditions, vegetation, host availability and mobility, grazing system and management practices $[5,6]$.

The Great Lakes region of Central Africa is characterised by cattle movement within and between countries for trade, breeding and pasture [7, 8]. During the pre-colonial period, immigrants originating from Rwanda and Burundi settled with their cattle in Congo in search of grazing lands. In addition, political unrest during the past three decades and rapidly increasing demand for animal products increased significantly the importation of live animals $[9,10]$. This cross-border movement of cattle across geographical areas, together with bioclimatic conditions suitable for $R$. appendiculatus, could play a significant role in spreading ticks and pathogens [11-14]. Therefore, the spread and establishment of ticks from one geographical region to another might be setting up a complexity in the epidemiological status and control of the disease they transmit [15-17]. Thus, predicting vector-borne pathogen dynamics and emergence relies on better understanding of mechanisms underlying the genetic structure of their vectors $[18,19]$.

Ecological establishment and population genetic structure of ticks can be affected by founder events and gene flow, largely due to their dispersal across geographical zones through host migration $[18,20]$. Arthropod vectors then respond differently to evolutionary forces such as migration, mutation, selection and genetic drift (promoted by bottlenecks) in their new environment [21, 22].
The adaptive mechanism of $R$. appendiculatus to changed environment suggests genetic divergence between geographical stocks and phenotypic variations, including diapause behaviour and vector competence to transmit $T$. parva $[23,24]$. The degree to which different $R$. appendiculatus stocks acquire and transmit T. parva is partially genetically dependent because of the heritability of their susceptibility to infection [25]. Furthermore, there is a similar extensive genetic variation among $T$. parva strains in the field associated with different clinical features and disease outcomes, and variable cross-immunity levels. Studies suggest that there are also specific interactions between $R$. appendiculatus and T. parva stocks in the transmission dynamic system, significantly affecting the epidemiology of ECF [26]. Thus, phylogenetic and ecological analyses should provide useful information to control ECF by determining: (i) the genetic structure of $R$. appendiculatus populations; (ii) its dispersal pattern; and (iii) its demographic history [27, 28].

The genetic diversity of $R$. appendiculatus has been studied in different African countries using various molecular tools, such as mitochondrial DNA [14, 29] and micro- and minisatellite DNA markers [30]. Two distinct genetic groups have been described, namely the eastern and the southern African lineages [29]. More recently, Kanduma et al. [31] found that the two genetic groups are present in Kenya. These evidences show that $R$. appendiculatus genetic groups may have a wide geographical range, with different ecological preferences and phenology in sub-Saharan Africa [32-34], due to differences in body size [35] and diapause induction and intensity [36, 37].

Major gaps in knowledge still exist concerning the agro-ecological colonization and establishment of the $R$. appendiculatus lineages in the Great Lakes region of Central Africa, where cattle mobility seems to be the main factor of tick dispersal and epidemic instability of ECF [2, 38]. Thus, further studies on the population structure and phylogeography of $R$. appendiculatus, including ticks from distinct agro-ecological conditions of DR Congo, Burundi and Rwanda, are important to shed light on the intra and inter population variation, the dispersal pattern and the 
historical dynamics of the characterised lineages in various ecological situations of Africa. The objective of this study was to assess the evolutionary relationship between $R$. appendiculatus populations and to investigate the impact of geographical locations on its genetic structure, to better understand the epidemiology of ECF in the Great Lakes region. To achieve this objective, we sequenced and analysed fragments of the cytochrome $c$ oxidase subunit 1 (cox 1$)$ and the $12 S$ ribosomal RNA (12S rRNA) gene loci. The genetic structure of $R$. appendiculatus provides clues to a better understanding of the epidemiology of ECF and insight into the development of targeted selective management and control strategies.

\section{Methods}

\section{Study area}

Ticks were collected from cattle in six agro-ecological zones (AEZs) of the Central African Great Lakes region (Democratic Republic of Congo, Rwanda and Burundi) (Fig. 1). The three countries share the Ruzizi Valley, which consists of lowlands along the Ruzizi River flowing between Lake Kivu and Lake Tanganyika. A summary description of the characteristics of the six AEZs is presented in Table 1. Briefly, although the study area is close to the equator, the wide range of altitudes (700 to $3000 \mathrm{~m}$ above sea level) mitigates significantly the tropical climate attributes and therefore the AEZs limits. Generally, the rainfall period is long and bimodal (with variations in the duration between AEZs). An early rainy season starts approximately in September and ends in December, while the late rainy season lasts from February to May, followed by a dry season from June to August. There is an intervening short dry period between the two rainy seasons of about 15 days in January and/or February depending on the AEZs. Rainfall and temperature are strongly influenced by altitude ranges. Rainfall increases while temperature decreases with increasing elevation. The average temperature ranges between $12-25{ }^{\circ} \mathrm{C}$ and the annual average rainfall from $800-1100 \mathrm{~mm}$ in the Ruzizi Valley to $1300-2000 \mathrm{~mm}$ in the highlands.

In eastern DRC, ticks were collected along an altitudinal transect in South-Kivu province. Based on elevation and geographical position within the transect, three major AEZs were defined from lowlands to highlands, namely, DRC AEZ1 (lowlands) in the Ruzizi Valley, DRC AEZ2 (midlands) in the administrative district of Walungu and DRC AEZ3 (highlands) in the district of Kabare and the highlands part of Walungu (Mulumemunene). The lowlands
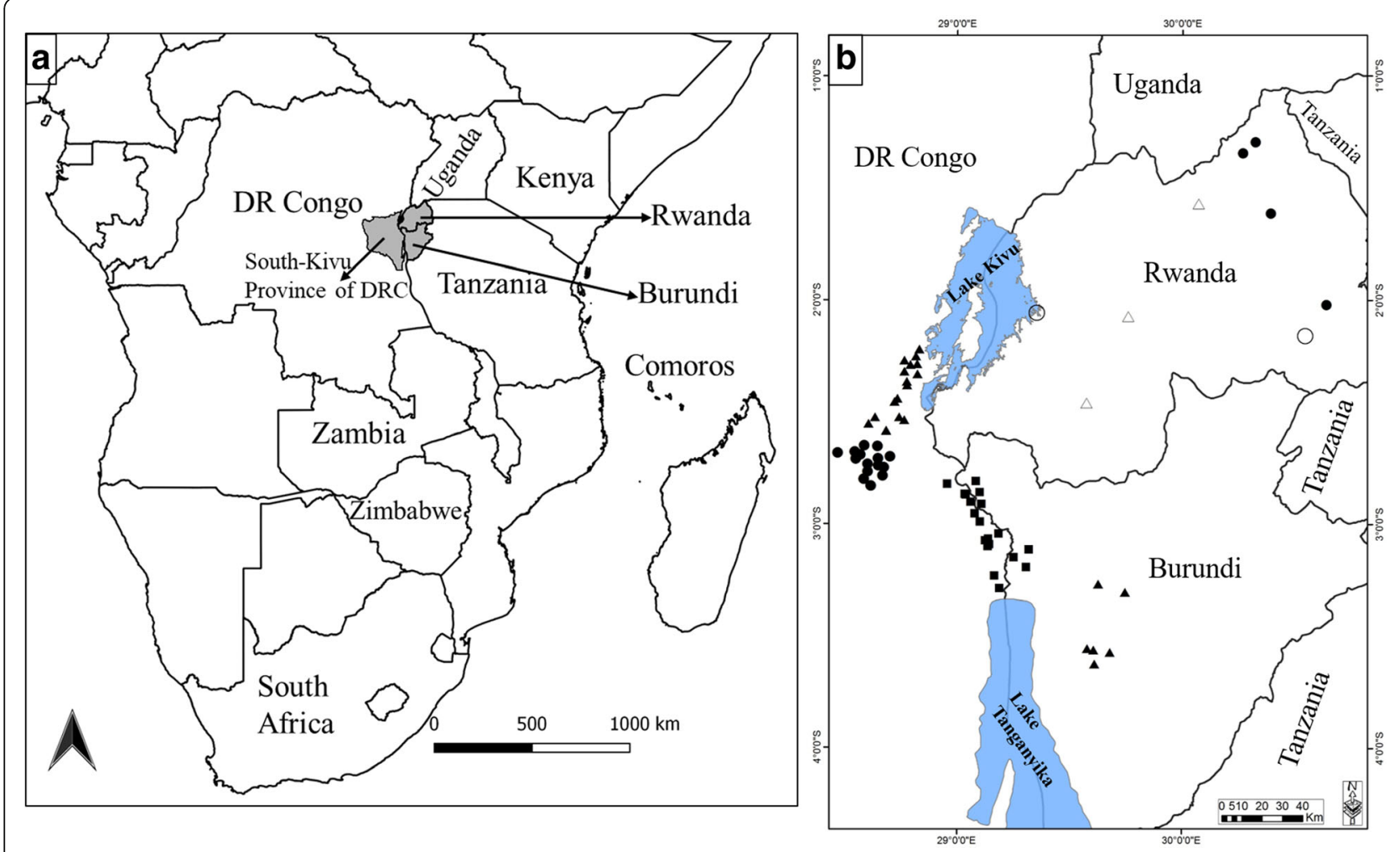

Fig. 1 Sampling sites of Rhipicephalus appendiculatus ticks in DRC, Rwanda and Burundi. a Map of Africa showing the study area (in grey) and other countries where the tick was previously sequenced (indicated by their names). b Sampling localities of $R$. appendiculatus and their altitudes (squares: AEZ1 altitude < 1200 m; circles: AEZ2 altitude 1200-1600 m; and triangles: AEZ3 altitude > 1600 m). The sites represented by empty circles and triangles show sampling locations described by Mtambo et al. [29] 
Table 1 Geographical and climatic attributes of the six agro-ecological zones (AEZ)

\begin{tabular}{lllllll}
\hline Country & Agro-ecological zone $(\mathrm{AEZ})$ & Altitude $(\mathrm{m})$ & Temperature $\left({ }^{\circ} \mathrm{C}\right)$ & Rainfall $(\mathrm{mm} /$ year) & Rainy season & Sample size $(\mathrm{no}$. of ticks) \\
\hline DRC & AEZ1 & $780-1100$ & $23-25$ & $800-1000$ & October-April & 46 \\
& AEZ2 & $1200-1600$ & $17-21$ & $1000-1500$ & September-May & 54 \\
& AEZ3 & $1600-2800$ & $12-19$ & $1350-2000$ & September-May & 46 \\
\multirow{2}{*}{ Burundi } & AEZ1 & $774-1100$ & $23-24$ & $800-1100$ & November-May & 26 \\
& AEZ3 & $1700-2800$ & $14-15$ & $1300-2000$ & September-May & 17 \\
Rwanda $^{a}$ & AEZ2 & $1200-1500$ & $21-24$ & $800-950$ & November-May & 20 \\
\hline
\end{tabular}

Notes: DRC (AEZ1: Lowlands, AEZ2: Midlands, AEZ3: Highlands); Burundi (AEZ1: Lowlands, AEZ3: Highlands); Rwanda (AEZ2: eastern low plateau which is the lowlands of Rwanda as described by Bazarusanga et al. [3])

${ }^{a}$ Sequences previously described in Mtambo at al. [29] are not included in the 20 samples from Rwanda and thus were not used in the population genetic analysis presented in Tables 2, 3 and 4

region (DRC AEZ1) is the warmest AEZ, characterised by a tropical dry climate (semi-arid), with a cool dry season of 4-5 months. Cattle are raised generally in an open grazing system in communal pastures of savannah grassland. In contrast, the "upland Kivu" (DRC AEZ2 and AEZ3) has a montane humid tropical climate and is much cooler. The warm dry season lasts for 3-4 months, with occasional and poorly distributed rainfall.

Ticks from Burundi were collected from two AEZs. The sampled administrative districts included Rugombo and Gihanga in the Imbo lowlands (Burundi AEZ1) and Muramvya, Mwaro and Mugamba districts of the Congo-Nile highlands (Burundi AEZ3). The Imbo region extends along the Ruzizi River and the North of Lake Tanganyika. The vegetation is composed of savannah and small patches of forest.

Ticks from Rwanda were obtained from the eastern low plateau in Nyagatare, Gatsibo and Kayonza districts (Rwanda AEZ2). This region includes the savannah of eastern province of Rwanda. The eastern semi-arid plateau zone is the most important pastoral region in Rwanda, holding $40 \%$ of the national herd raised in a communal grazing system. The vegetation type is largely savannah and some river bank woods.

\section{Tick sampling and morphological identification}

Ticks were collected from cattle during a cross-sectional survey conducted from February to April 2015 (late rainy season) in the six AEZs. In each AEZ, 8 to 12 cattle herds were selected randomly using a random number generator in Microsoft Excel. From ticks collected in each herd representing a location or village, 4 to 5 ticks were selected using the same random process for further analysis. The number of ticks sampled in each population is shown in Table 1. All ticks were directly immersed in $70 \%$ ethanol for preservation and morphologically identified using the identification key of Walker et al. [39]. Morphological identification was confirmed at the tick unit at the International Livestock Research Institute (ILRI, Kenya). Ten additional specimens originating from Simanjiro district in northern Tanzania were obtained from the Sokoine University of Agriculture in Tanzania.

\section{DNA extraction, PCR amplification and sequencing}

Total genomic DNA was isolated from whole individual ticks using the DNeasy ${ }^{\odot}$ Blood and Tissue Kit (Qiagen $\mathrm{GmbH}$, Hilden, Germany) according to the standard manufacturer's protocol, except that an additional incubation of $10 \mathrm{~min}$ at $56{ }^{\circ} \mathrm{C}$ was added after mixing the sample with $200 \mu \mathrm{l}$ buffer AL to ensure optimal cell lysis. Prior to extract DNA, ticks were washed twice in double distilled water and left to dry for $10 \mathrm{~min}$ at room temperature and homogenized by grinding.

Given the suitability of mitochondrial genes to discriminate intraspecific variation in ticks [29, 31], we amplified the cox 1 and $12 S$ rRNA gene loci to assess the genetic diversity and phylogenetic relationships of $R$. appendiculatus populations. A $710 \mathrm{bp}$ fragment of cox 1 gene locus was amplified with the forward primer LCO1490 (5'-GGT CAA CAA ATC ATA AAG ATA TTG G-3') and the reverse primer HC02198 (5'-TAA ACT TCA GGG TGA CCA AAA AAT CA-3') as previously described by Folmer et al. [40]; for the $12 \mathrm{~S}$ rRNA gene locus we used the primers SR-J-1499 (5'-TAC TAT GTT ACG ACT TAT-3') and SR-N-14594 (5'-AAA CTA GGA TTA GAT ACC C-3') with a fragment size of 380 bp, described in Simon et al. [41]. PCR amplifications of both cox 1 and $12 S$ rRNA gene fragments were performed using $50 \mathrm{ng}$ of genomic DNA, $25 \mu \mathrm{l}$ of $2 \times$ AccuPower ${ }^{\circ}$ PCR PreMix (Bioneer PCR-PreMix, Seoul, South Korea), $0.2 \mu \mathrm{M}$ each of forward and reverse primers, and nuclease free water added up to a final reaction volume of $50 \mu \mathrm{l}$. The thermal cycling program for $\operatorname{cox} 1$ consisted of an initial denaturation at $95^{\circ} \mathrm{C}$ for 3 min followed by 35 cycles of denaturation at $94{ }^{\circ} \mathrm{C}$ for $1 \mathrm{~min}$, annealing at $40{ }^{\circ} \mathrm{C}$ for $1 \mathrm{~min}$ and extension at $72{ }^{\circ} \mathrm{C}$ for $1 \mathrm{~min}$. The final extension was carried out for $10 \mathrm{~min}$ at $72{ }^{\circ} \mathrm{C}$. PCR parameters of $12 S$ rRNA gene fragment were as described for $\operatorname{cox} 1$, except that the annealing temperature was $52{ }^{\circ} \mathrm{C}$ and the extension time was $90 \mathrm{~s}$. PCR products were analysed by electrophoresis on a $1.8 \%$ agarose 
gel. Amplicons were purified using the QIAquick ${ }^{\circ}$ PCR Purification Kit (Qiagen GmbH, Hilden, Germany) following the manufacturer's instructions. Both strands were sequenced directly with the same primers used for PCR, on an ABI 3730 capillary sequencer (Applied Biosystems, California, USA).

\section{Sequences editing, blasting and multiple alignments}

Forward and reverse chromatograms for each individual tick were visually checked. Sequences were manually edited and assembled using CLC Main Workbench software v7.8.1 (CLC Bio, Aarhus, Denmark). Multiple sequences were aligned with CrustalW algorithm using default settings in the same software. The sequences were then trimmed to exclude poor quality bases and obtain uniform sizes. The final sequence sizes were 586 bp and 346 bp for cox 1 and $12 S$ rRNA genes, respectively. Aligned and trimmed sequences were subjected to a BLAST search against all NCBI nucleotide databases, with default settings to confirm their species identity. A total of 219 sequences for cox 1 and 126 for $12 S$ were obtained after quality check processing. To check for amplification of nuclear pseudogenes and confirm protein coding, all cox 1 nucleotide sequences were translated into their amino acid sequences to examine the presence of ambiguous stop codons for correct coding of invertebrate mitochondrial DNA.

\section{Genetic diversity and population genetic structure}

Multiple sequences extracted from the alignments were used to construct haplotypes in DnaSP software v5.10.01 [42]. Genetic variation within populations was estimated on $\operatorname{cox} 1$ gene sequences. Population genetic indices represented by number of haplotypes $(h)$, number of segregating sites $(S)$, haplotype diversity $(H d)$, mean number of pairwise nucleotide differences within population $(K)$ and nucleotide diversity $(\pi)$ were calculated for each AEZs (named populations) and for the overall data set using Arlequin v3.5.2.2 [43] and DnaSP. The population genetic structure among AEZs and among haplogroups was evaluated by an analysis of molecular variance (AMOVA) performed in Arlequin. The significance of AMOVA fixation indices was evaluated based on 1,023 random permutations. In addition, to assess the level of genetic distance/differentiation between populations, we estimated gene flow expressed as of the absolute number of migrants $(\mathrm{Nm})$ exchanged among populations, average number of nucleotide differences between populations $\left(K_{X Y}\right)$ and population pairwise genetic differentiation $\left(F_{S T}\right)$ also in Arlequin [44]. Their significance was tested using 1000 random permutations. The genetic differentiation and population structure statistics were tested under the hypothesis that different populations are represented by distinct genetic groups or are exchanging migrants. These analyses were performed for combined data (of the main haplogroups identified) to understand the effect of coexistence of the haplogroups in the genetic structure and diversity.

\section{Demographic and spatial expansion history analyses}

The historical population dynamics and structure was inferred from mismatch distribution of cox 1 haplotypes implemented in Arlequin [45], which compared the observed distribution of pairwise nucleotide differences between haplotypes and that expected under a population expansion model for each population, haplogroup and overall data. Multimodal mismatch pattern is assumed to define a population of demographic equilibrium or constant size, whereas sudden or expanding population is characterised by unimodal distribution. The sum of square deviation $(S S D)$ were estimated to determine if the observed mismatch deviated significantly from a population expansion model, and the Harpending's raggedness index $(R I)$ were used to evaluate the smoothness of mismatch distribution [46]. In addition, to detect deviation from neutrality expectations or mutation-drift equilibrium we performed analysis of Fu's $F s$ [47] and Tajima's $D$ [48] statistics in Arlequin and DnaSP. Tajima's $D$ test is based on the difference between the number of polymorphic sites and the mean number of nucleotide pairwise differences, while Fu's $F s$ test is based on haplotype frequencies. The significance of all these statistics was tested by bootstrap resampling of 1000 coalescent simulations. Significant negative values of neutrality statistics should indicate a signature of historical event of population expansion, whereas significantly positive values indicate events such as recent population bottleneck, population subdivision or presence of some recent immigrants in a population. Values near zero and not significant, indicate that population size is constant.

\section{Phylogenetic and phylogeographical reconstruction}

Different published haplotype sequences of $R$. appendiculatus from South Africa, Kenya, Grande Comore, Zambia, Zimbabwe, Uganda and Rwanda were retrieved from the National Center for Biotechnology Information (NCBI) database (see Additional file 1: Table S1) and were compared with sequences obtained in the present study. Phylogenetic reconstruction was performed separately on $\operatorname{cox} 1$ and $12 S$ rRNA gene sequences to determine the relationship among populations and possible historical dispersal event. To find the evolutionary substitution model that best describe the evolution of $\operatorname{cox} 1$ and $12 S$ rRNA gene sequences, we performed a hierarchical likelihood ratio test, based on the lowest Bayesian information criterion using MEGA v7.0 [49]. The nucleotide substitution model selected was then used to 
perform a Neighbor-Joining (NJ) and/or Maximum Likelihood (ML) algorithm in MEGA. The stability and branches support were obtained using 1000 bootstrap permutations. Rhipicephalus eversti and Rhipicephalus microplus from this study (GenBank accession numbers MF458972 and MF458973 for cox1 and MF479198 and MF479199 for 12S RNA genes) and Rhipicephalus turanicus obtained from the GenBank (accession numbers KU880574 and DQ849231 for cox1 and 12S rRNA genes, respectively) were used as outgroup taxa. A Median-Joining (MJ) network was constructed to investigate the phylogenetic and ancestral relationship among haplotypes using PopArt Software [50].

\section{Results}

\section{Morphological and molecular identification of ticks}

PCR fragments of the mitochondrial cox 1 and $12 S$ rRNA gene loci were successfully generated from 219 and 126 individual ticks, respectively, originating from the three AEZs of DRC, the two AEZs of Burundi, one AEZ of Rwanda and specimens from Tanzania. The 10 sequences from Tanzania and the sequences previously described in Rwanda were not included in the population genetic and structure analyses. Generated nucleotide sequences were aligned with the reference haplotype sequences retrieved from the GenBank (Additional file 1: Table S1). The final fragment length obtained for $\operatorname{cox} 1$ was $586 \mathrm{bp}$ and $12 S$ rRNA yielded a fragment of $346 \mathrm{bp}$ long, with no indels detected in both genes. Their morphological identification has been confirmed by the high molecular identity (99-100\%) with known sequences of $R$. appendiculatus found in GenBank (Additional file 2: Table S2). Haplotype sequences (55 and 23 sequences for cox 1 and $12 S$ rRNA, respectively) obtained for each of the six AEZs were deposited and are available in GenBank (GenBank accession numbers: MF458895-MF458949 and MF479166-MF479188 for cox 1 and $12 S$ rRNA genes, respectively).

\section{Phylogenetic relationships and haplotypes distribution}

The overall sequence analysis revealed that $\operatorname{cox} 1$ had 27 polymorphic sites, 21 of which were parsimony informative and 6 were singletons, yielding 22 haplotypes (Additional file 3: Table S3). cox1 amino acid sequences did not contain any internal stop codon or indel. Most nucleotide mutations were synonymous, except one non-synonymous change identified at position 32 of the haplotype $\mathrm{CH} 22$ (change from an Alanine to a Threonine). The highest number of $\operatorname{cox} 1$ haplotypes was found in DRC AEZ1, while the lowest was observed in Burundi AEZ3 (Table 2). The $12 S$ rRNA gene provided 10 polymorphic sites, five of which were parsimony informative, defining 9 haplotypes. The 22 cox 1 haplotype sequences obtained in this study were submitted to GenBank under accession numbers MF458950-MF458971 and the nine $12 S$ rRNA gene haplotypes were deposited under accession numbers MF479189-MF479197. The phylogenetic relationships among cox 1 haplotypes inferred by a NJ phylogenetic tree (Fig. 2), a ML tree (Fig. 3) and a MJ network (Fig. 4) produced identical topologies and detected

Table 2 Rhipicephalus appendiculatus cox1 haplotypes distribution (\%) and genetic diversity indices in six agro-ecological zones of the Democratic Republic of Congo, Burundi and Rwanda

\begin{tabular}{|c|c|c|c|c|c|c|c|c|c|c|}
\hline \multirow[t]{2}{*}{ Country } & \multirow[t]{2}{*}{ AEZ } & \multirow[t]{2}{*}{$n$} & \multirow[t]{2}{*}{ h } & \multirow[t]{2}{*}{ Haplotype (frequency in \%), } & \multicolumn{2}{|c|}{$\begin{array}{l}\text { Haplogroup } \\
\text { (\%) }\end{array}$} & \multicolumn{4}{|c|}{ Genetic diversity indices } \\
\hline & & & & & A & B & $\begin{array}{l}\mathrm{S} \\
(\mathrm{PIS})\end{array}$ & $H d(S D)$ & K & $\pi(\mathrm{SD})$ \\
\hline \multirow[t]{3}{*}{$\mathrm{DRC}$} & AEZ1 & 46 & 10 & 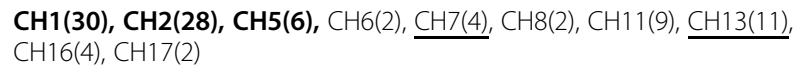 & 85 & 15 & $\begin{array}{l}17 \\
(16)\end{array}$ & $\begin{array}{l}0.82 \\
(0.03)\end{array}$ & $4.4(2.2)$ & $\begin{array}{l}0.007 \\
(0.002)\end{array}$ \\
\hline & AEZ2 & 54 & 12 & 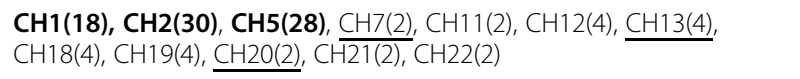 & 92 & 8 & $\begin{array}{l}20 \\
(17)\end{array}$ & $\begin{array}{l}0.81 \\
(0.03)\end{array}$ & $3.1(1.6)$ & $\begin{array}{l}0.005 \\
(0.001)\end{array}$ \\
\hline & AEZ3 & 46 & 7 & 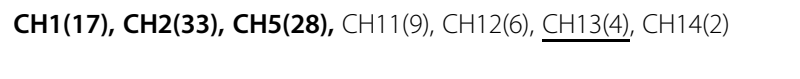 & 96 & 4 & $\begin{array}{l}16 \\
(15)\end{array}$ & $\begin{array}{l}0.79 \\
(0.03)\end{array}$ & $2.4(1.3)$ & $\begin{array}{l}0.004 \\
(0.001)\end{array}$ \\
\hline \multirow[t]{2}{*}{ Burundi } & AEZ1 & 26 & 8 & $\mathrm{CH} 1$ (50), $\mathrm{CH} 2$ (19), $\mathrm{CH} 3(4), \mathrm{CH} 4(4), \mathrm{CH} 5(11), \mathrm{CH} 6(4), \mathrm{CH} 7(4), \mathrm{CH} 10(4)$ & 96 & 4 & $\begin{array}{l}18 \\
(3)\end{array}$ & $\begin{array}{l}0.72 \\
(0.08)\end{array}$ & $2.01(1.2)$ & $\begin{array}{l}0.003 \\
(0.001)\end{array}$ \\
\hline & AEZ3 & 17 & 5 & $\mathrm{CH} 1(29), \mathrm{CH} 2(35), \mathrm{CH} 5(23), \mathrm{CH} 8(6), \mathrm{CH} 9(6)$ & 100 & 0 & $4(2)$ & $\begin{array}{l}0.77 \\
(0.06)\end{array}$ & $1.1(0.9)$ & $\begin{array}{l}0.002 \\
(0.0003)\end{array}$ \\
\hline Rwanda & AEZ2 & 20 & 8 & $\begin{array}{l}\mathrm{CH} 1(30), \mathrm{CH} 2(20), \mathrm{CH} 4(5), \mathrm{CH} 5(5), \underline{\mathrm{CH} 7(20)}, \mathrm{CH} 11(5), \underline{\mathrm{CH} 13(10)}, \\
\mathrm{CH} 15(5)\end{array}$ & 70 & 30 & $\begin{array}{l}18 \\
(13)\end{array}$ & $\begin{array}{l}0.85 \\
(0.05)\end{array}$ & $6.3(3.1)$ & $\begin{array}{l}0.011 \\
(0.002)\end{array}$ \\
\hline Total & & 209 & 22 & - & 90 & 10 & $\begin{array}{l}27 \\
(21)\end{array}$ & $0.81(0.01)$ & $3.4(1.7)$ & $\begin{array}{l}0.006 \\
(0.0006)\end{array}$ \\
\hline
\end{tabular}

Abbreviations: $A E Z$ agro-ecological zones, $n$ number of sequences, h number of haplotypes, $S$ segregation sites, $P I S$ parsimony informative sites, $H d$ haplotype diversity, $S D$ standard deviation; $K$ mean number of pairwise nucleotide differences, $\pi$ nucleotide diversity, $C H 1-22$ names of cox 1 haplotypes

${ }^{\mathrm{a}}$ Haplotypes belonging to the haplogroup $\mathrm{B}$ are underlined

${ }^{b}$ Bold indicates shared haplotypes by all agro-ecological zones

${ }^{\mathrm{C}} \mathrm{A}$ and $\mathrm{B}$ are haplogroup names 


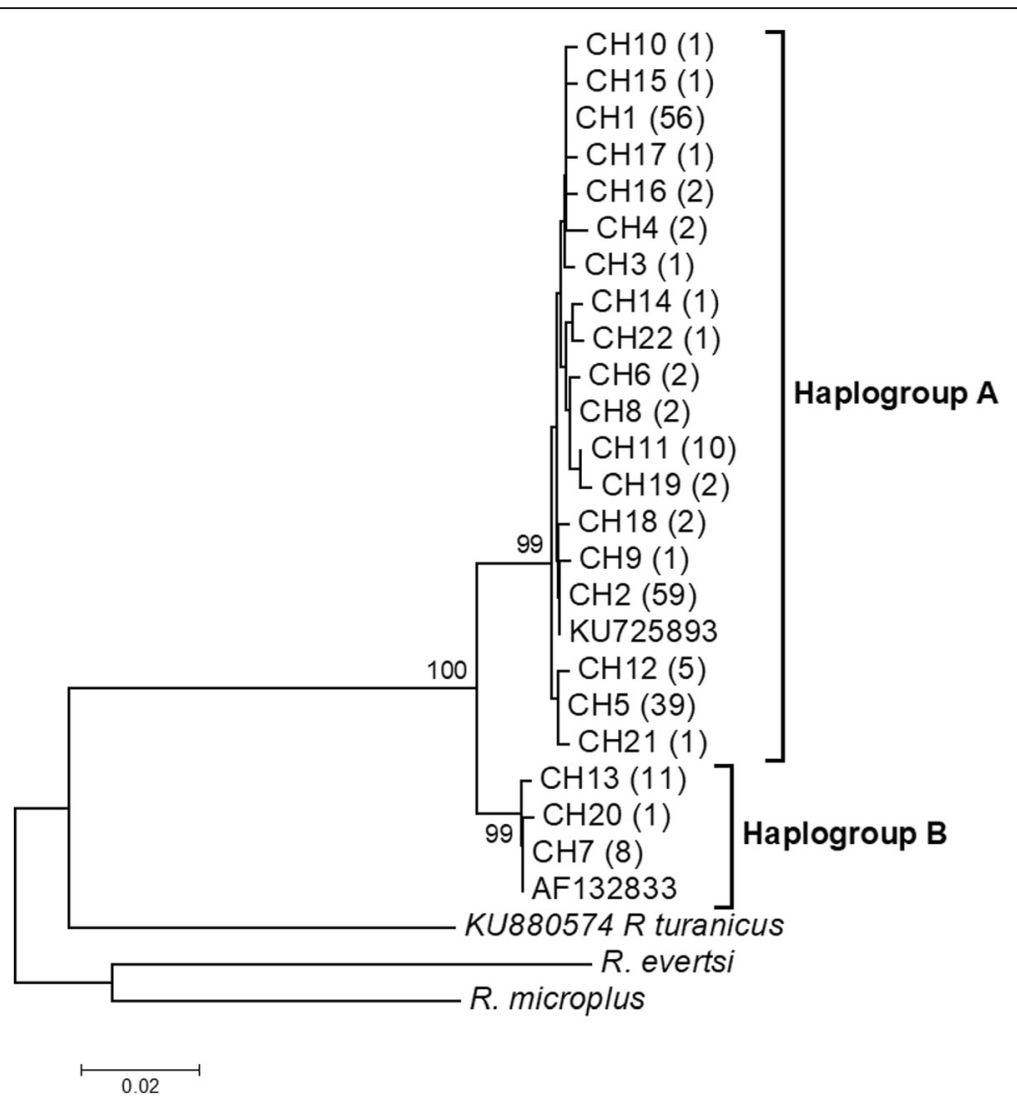

Fig. 2 Phylogenetic tree of $R$. appendiculatus cox 1 haplotypes. The evolutionary history was inferred by using the neighbor-joining method based on the Tamura 3-parameter model. A discrete Gamma distribution was used to model evolutionary rate differences among sites. Bootstrap values (> 80) are displayed above nodes. $\mathrm{CH1}-22$ are haplotype names. The values in parentheses correspond to the frequency of each haplotype. KU725893 and AF132833 are GenBank accession numbers for $R$. appendiculatus sequences used as reference haplotypes from Kenya and Zimbabwe, respectively. Two species (R. eversti and R. microplus) obtained in this study and R. turanicus from GenBank (accession number: KU880574) were included as outgroups

two distinct clades or lineages strongly-supported by a NJ bootstrap value of $100 \%$. The two lineages diverged at least by 12 mutational steps (Additional file 3: Table S3) but shared a wide range of agro-ecological and geographical conditions in the Great Lakes region. The first lineage, named "haplogroup A", was represented by the most frequent haplotypes $(\mathrm{CH} 1, \mathrm{CH} 2$ and $\mathrm{CH} 5)$ and comprised in total 19 haplotypes consisting of 189 of the 209 sequences analysed (90\%), whereas the second lineage "haplogroup B" included three haplotypes $(\mathrm{CH} 7, \mathrm{CH} 13, \mathrm{CH} 20)$ and had a total of 20 sequences (10\%) (Fig. 2, Additional file 3: Table S3). Haplogroup B comprised of haplotypes present in most AEZs except the highlands region of Burundi (Burundi AEZ3). These cox1 haplogroups presented a star-like pattern in the MJ network with less frequent and single haplotypes connected together to the predominant or ancestral haplotypes generally by single substitutions (Fig. 4), supporting the hypothesis of a recent population expansion. The phylogenetic relationships found in the cox 1 gene were fully congruent with those revealed by the ML tree performed on $12 S$ rRNA haplotypes.
The distribution of haplotypes presented in Table 2 showed that there were shared and private $\operatorname{cox} 1$ haplotypes confined to restricted AEZs. Three haplotypes $\mathrm{CH} 1$ (27\%), $\mathrm{CH} 2$ (28\%) and $\mathrm{CH} 5$ (19\%) were shared between all AEZs and were by far the most ubiquitous in the region, accounting for $74 \%$ (154 sequences) of the overall dataset (Additional file 3: Table S3). Haplotype $\mathrm{CH} 1$ was detected in 13 (50\%) of the 26 sequences from lowlands of Burundi (Burundi AEZ1). Two haplotypes (CH11 and $\mathrm{CH} 13)$ defined by 10 and 11 sequences, respectively, were common in all the AEZs of DRC and in Rwanda AEZ2. Haplotype CH12 was exclusive to DRC AEZ2 and AEZ3. Nine out of the 22 haplotypes were found in single individuals; therefore, they belonged to particular AEZs (Additional file 3: Table S3). Furthermore, two $12 \mathrm{~S}$ rRNA haplotypes (12SH1 and 12SH2) were the most abundant, representing $90 \%$ of the 126 sequences analysed. Haplotypes $12 \mathrm{SH} 4$ and $12 \mathrm{SH} 5$ had together $8(6 \%)$ out of the 126 analysed sequences. The presence of single haplotypes indicates high frequency of rare alleles, which suggests a recent population expansion. 


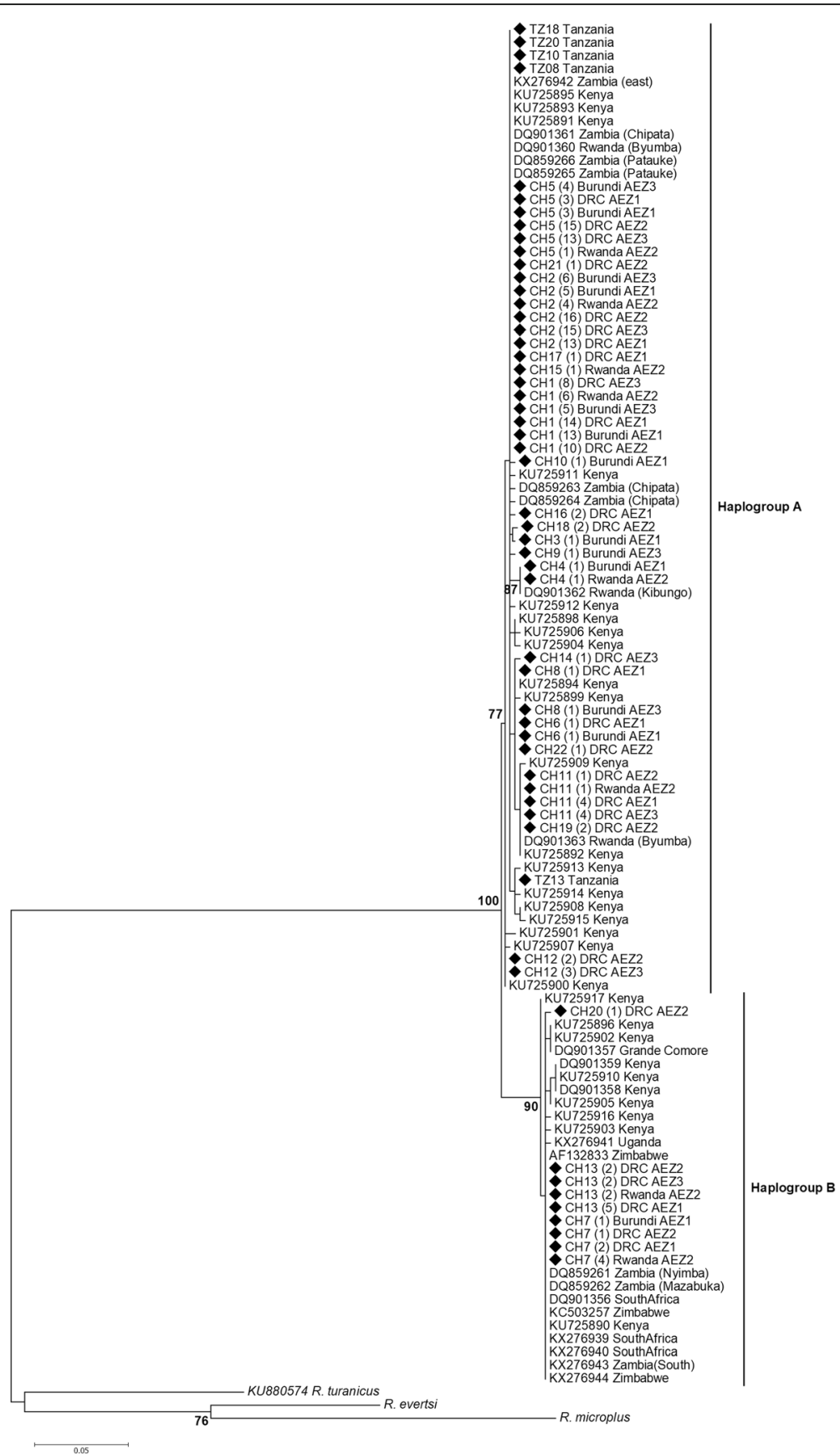

Fig. 3 Phylogenetic tree of cox 1 haplotypes displaying the relationship between the $R$. appendiculatus specimens in sub-Saharan African countries. The evolutionary history was inferred by using the maximum likelihood method based on the Tamura 3-parameter model. A discrete Gamma distribution was used to model evolutionary rate differences among sites [5 categories $(+G$, parameter $=0.39)$ ]. The tree is drawn to scale, with branch lengths measured in the number of substitutions per site. Bootstrap scores $>70$ are displayed to support nodes. The values in bracket behind haplotype names correspond to the frequency of each haplotype. Haplotype sequences (CH1-22) obtained in the present study are indicated by a black square. Rhipicephalus eversti and R. microplus obtained in this study and R. turanicus (GenBank number: KU880574) were used as outgroups

\section{Population genetic diversity}

Population genetic indices were estimated using cox1 nucleotide sequences and are shown in Table 2. The overall haplotype diversity $(H d)$ and nucleotide diversity $(\pi)$ were 0.81 and 0.006 , respectively. The haplotype diversity ranged from 0.72 in Burundi AEZ1 to 0.85 in Rwanda AEZ2 and the nucleotide diversity $(\pi)$ values ranged from 0.002 in Burundi AEZ3 to 0.011 in Rwanda AEZ2. The average number of nucleotide pairwise differences (k) was 3.4 for the overall dataset, with the highest value observed in 


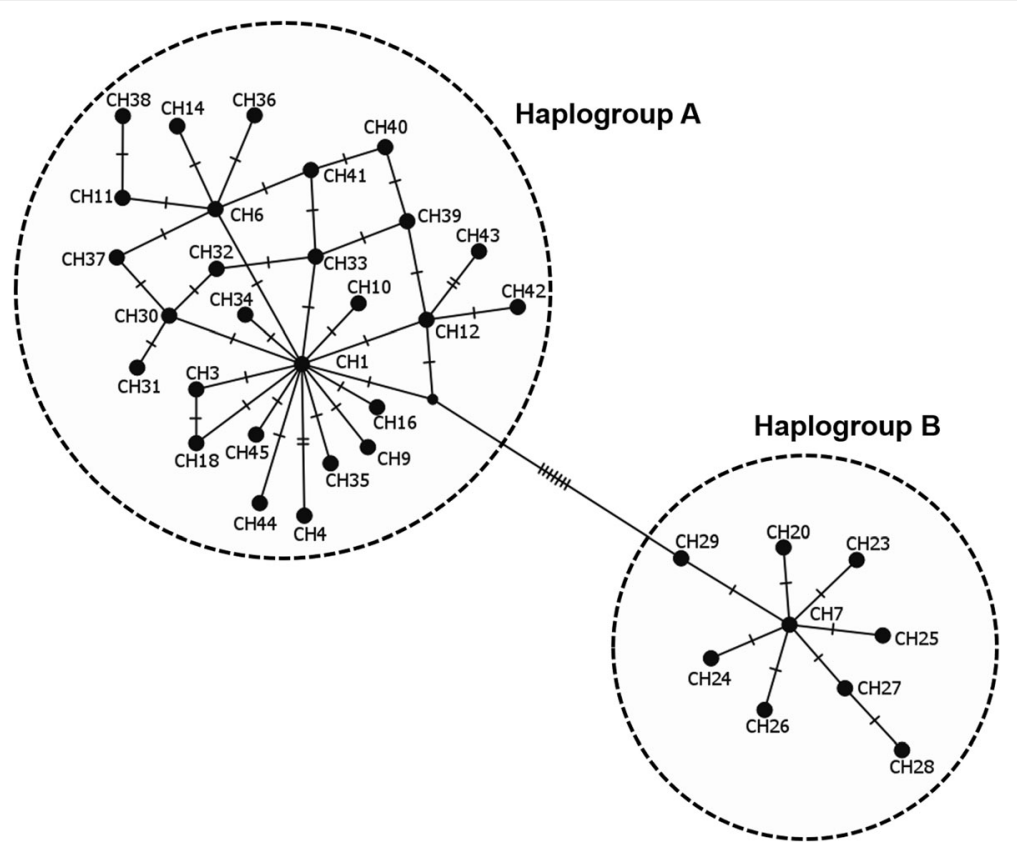

Fig. 4 Median-joining network of the 36 cox 1 haplotypes for $R$. appendiculatus ticks across sub-Saharan African countries. Lines represent mutations and the dot corresponds to a possible intermediate haplotype. Each circle denotes a unique haplotype. Haplotype frequencies are not shown here, but their occurrences across Africa are presented in Table 5

Rwanda AEZ2 (6.3). Altogether, these population genetic indices showed that the diversity of $R$. appendiculatus is quite different among AEZs. Ticks from Rwanda AEZ2 were more highly diverse than those from three AEZs of DRC and the two AEZs of Burundi. We also observed an excess of singleton mutations in Burundi AEZ1 (15 out of 18 polymorphic sites), suggesting a sudden population expansion. These data analysed separately by haplogroups (Table 3), showed that the differences of genetic diversity among AEZs was largely affected by the frequency distribution of the two cox1 haplogroups (Table 2).

\section{Population structure and ecological differentiation based on cox 1 haplotypes}

Analysis of molecular variance (AMOVA) based on cox1 sequences revealed statistically significant variance among the six AEZs analysed together for both combined haplogroups and haplogroup A alone $(6 \%, P<0.001)$ (Additional file 4: Table S4). The genetic variability among individuals within AEZs explained the large majority of molecular variance (94\%) for the overall dataset, suggesting an admixture between different populations and the coexistence of the two genetically divergent lineages (Fig. 2, Table 2). This is consistent with moderate genetic structure of $R$. appendiculatus in the Great Lakes region. The population differentiation indices were then calculated to compare the genetic variation observed among AEZs (Table 4). Both differentiation statistics based on pairwise estimates of the Inter-population nucleotide differences
$\left(K_{X Y}\right)$, the pairwise genetic distance $\left(F_{S T}\right)$, and the number of migrants $(\mathrm{Nm})$ showed evidence of differentiation between some $R$. appendiculatus populations. The population pairwise genetic distance $\left(F_{S T}\right)$ varied from a negative and not significant value $\left(F_{S T}=-0.014, P=0.87\right)$ with infinite value of $\mathrm{Nm}$ (between DRC AEZ2 and AEZ3) to the strongest differentiation $\left(F_{S T}=0.19, P=0.005\right)$ with low number of migrants $(\mathrm{Nm}=2.1)$ between Burundi AEZ3 and Rwanda AEZ2. Pairwise $F_{S T}$ values were found to be low and not significant between DRC AEZ3 and Burundi AEZ3 with infinite $\mathrm{Nm}$ and between DRC AEZ2 and Burundi AEZ3 associated to a high number of migrants $(N m=11,875)$, indicating an excess of gene flow between these zones. DRC AEZ1 did not differ significantly with Burundi AEZ1 $\left(F_{S T}=0.022, P=0.19\right)$ and Rwanda $\operatorname{AEZ2}\left(F_{S T}=0.018, P=0.24\right)$. Tick populations from Rwanda AEZ2 showed a strong genetic differentiation with those from DRC AEZ3 $\left(F_{S T}=0.18, P<0.001\right)$ and DRC $\operatorname{AEZ2}\left(F_{S T}=0.14, P=0.03\right)$, indicating reduced or lack of gene flow between these populations. These results were confirmed by inter-population nucleotide differences $\left(K_{X Y}\right)$, which was significant when populations were significantly differentiated by the pairwise $F_{S T}$ statistic. Tick populations were compared by analysing haplogroup A sequences alone. The findings showed that ticks from Rwanda AEZ2 and the two AEZs of Burundi were not genetically different. They shared more migrants belonging to haplogroup A (Table 4). In general, the population differentiation was observed between lowlands and highlands AEZs. 
Table 3 Genetic diversity and evolutionary dynamics of the two haplogroups ( $\mathrm{A}$ and $\mathrm{B}$ ) identified from cox 1 sequences of $R$. appendiculatus

\begin{tabular}{|c|c|c|c|c|c|c|c|c|c|}
\hline \multirow{3}{*}{$\begin{array}{l}\text { Genetic indices and } \\
\text { statistics }\end{array}$} & \multicolumn{7}{|c|}{ Haplogroup A } & \multirow{3}{*}{$\begin{array}{l}\text { Haplogroup } \\
\text { B }\end{array}$} & \multirow{3}{*}{$\begin{array}{l}\text { Overall data } \\
\text { set }\end{array}$} \\
\hline & \multicolumn{3}{|l|}{$\overline{\mathrm{DRC}}$} & \multicolumn{2}{|l|}{ Burundi } & \multirow{2}{*}{$\begin{array}{l}\text { Rwanda } \\
\text { AEZ2 }\end{array}$} & \multirow{2}{*}{$\begin{array}{l}\text { Haplogroup } \\
\text { A (overall) }\end{array}$} & & \\
\hline & $\overline{\mathrm{AEZ1}}$ & AEZ2 & AEZ3 & $\overline{\mathrm{AEZ1}}$ & AEZ3 & & & & \\
\hline \multicolumn{10}{|l|}{ Diversity indices } \\
\hline Number of sequences & 39 & 50 & 44 & 25 & 17 & 14 & 189 & 20 & 209 \\
\hline $\begin{array}{l}\text { Number of polymorphic } \\
\text { sites }\end{array}$ & 7 & 9 & 6 & 8 & 4 & 7 & 18 & 2 & 27 \\
\hline Number of haplotypes & 8 & 9 & 6 & 7 & 5 & 6 & 19 & 3 & 22 \\
\hline Haplotype diversity (SD) & $0.76(0.044)$ & $0.78(0.032)$ & $0.77(0.033)$ & $0.7(0.084)$ & $0.77(0.057)$ & $0.77(0.089)$ & $0.77(0.016)$ & $0.56(0.063)$ & $0.81(0.01)$ \\
\hline Nucleotide diversity (SD) & $\begin{array}{l}0.002 \\
(0.0003)\end{array}$ & $\begin{array}{l}0.0025 \\
(0.0003)\end{array}$ & $\begin{array}{l}0.002 \\
(0.0003)\end{array}$ & $\begin{array}{l}0.002 \\
(0.0004)\end{array}$ & $\begin{array}{l}0.002 \\
(0.0003)\end{array}$ & $\begin{array}{l}0.002 \\
(0.0006)\end{array}$ & $\begin{array}{l}0.002 \\
(0.0001)\end{array}$ & $\begin{array}{l}0.001 \\
(0.0002)\end{array}$ & $\begin{array}{l}0.006 \\
(0.0006)\end{array}$ \\
\hline \multicolumn{10}{|l|}{ Neutrality tests } \\
\hline Tajima's D ( $P$-value $)$ & $-0.6(0.35)$ & $-0.79(0.23)$ & $0.096(0.6)$ & $\begin{array}{l}-1.4 \\
(0.049)^{*}\end{array}$ & $-0.21(0.45)$ & $-1.4(0.07)$ & $-1.5(0.032)^{*}$ & $0.24(0.67)$ & $-0.93(0.23)$ \\
\hline Fu's Fs ( $P$-value) & $-2.4(0.08)$ & $-2.5(0.097)$ & $-0.1(0.49)$ & $\begin{array}{l}-2.6 \\
(0.027)^{*}\end{array}$ & $-1.1(0.18)$ & $\begin{array}{l}-2.1 \\
(0.041)^{*}\end{array}$ & $\begin{array}{l}-10.4 \\
(0.001)^{*}\end{array}$ & $0.2(0.49)$ & $-3.8(0.15)$ \\
\hline \multicolumn{10}{|l|}{ Demographic expansion } \\
\hline $\begin{array}{l}\text { Sum of Squared deviation } \\
(P \text {-value })\end{array}$ & $0.002(0.66)$ & $0.004(0.31)$ & $0.002(0.49)$ & $0.002(0.72)$ & $0.02(0.17)$ & $0.001(0.9)$ & $\begin{array}{l}0.0008 \\
(0.44)\end{array}$ & $\begin{array}{l}0.029 \\
(0.049)^{*}\end{array}$ & $0.017(0.1)$ \\
\hline $\begin{array}{l}\text { Harpending's Raggedness } \\
\text { index ( } P \text {-value) }\end{array}$ & $0.06(0.39)$ & $0.079(0.21)$ & $0.06(0.38)$ & $0.05(0.71)$ & $0.16(0.12)$ & $0.06(0.73)$ & $0.057(0.2)$ & $0.21(0.1)$ & $0.049(0.51)$ \\
\hline \multicolumn{10}{|l|}{ Spatial expansion } \\
\hline $\begin{array}{l}\text { Sum of Squared deviation } \\
(P \text {-value })\end{array}$ & $0.002(0.5)$ & $0.004(0.21)$ & $0.002(0.4)$ & $0.002(0.67)$ & $0.02(0.1)$ & $0.001(0.9)$ & $\begin{array}{l}0.0008 \\
(0.26)\end{array}$ & $\begin{array}{l}0.029 \\
(0.011)^{*}\end{array}$ & $0.036(0.28)$ \\
\hline $\begin{array}{l}\text { Harpending's Raggedness } \\
\text { index } \\
(P \text {-value })\end{array}$ & $0.064(0.39)$ & $0.079(0.21)$ & $0.062(0.43)$ & $0.05(0.75)$ & $0.16(0.12)$ & $0.06(0.72)$ & $0.057(0.22)$ & $0.21(0.12)$ & $0.049(0.74)$ \\
\hline
\end{tabular}

Abbreviations: $D$ Tajima's neutrality statistic, $F s$ Fu's neutrality statistic

*Values are statistically significant at $P<0.05$; significance was determined using 1000 coalescent simulations

Demographic and dispersal dynamics of $R$. appendiculatus Demographic and spatial dynamics inferred from pairwise nucleotide differences revealed bimodal pattern for the total dataset (Fig. 5a). Tajima's $D$ and Fu's $F s$ were negative but not significant (Table 3). However, the sum of square deviation $(S S D)$ and raggedness index $(R I)$ for both demographic and range expansion did not deviate significantly from that expected under expansion model. The negative values of neutrality tests and the non-significance of $S S D$ and $R I$ indices, suggest a sudden expansion of $R$. appendiculatus populations in the Great Lakes region. The population dynamics history was also analysed separately for each of the six AEZs (Fig. 6, Additional file 5: Table S5). Most AEZs showed a bimodal mismatch distribution, except in Burundi AEZ3 where the mismatch pattern was unimodal (Fig. 6e). The observed bimodal pattern suggested population subdivision as shown by the existence of two well resolved haplogroups (Fig. 2).

The population dynamics were then inferred for each haplogroup separately (Table 3). A unimodal distribution was observed in both haplogroups (Fig. 5b, c). For the haplogroup A, we detected significant evidence of demographic and spatial expansion events from the unimodal mismatch distribution, together with significantly negative values for Tajima's $D(D=-1.5, P=0.032)$ and Fu's $F s(F s=-10.4, P=0.001)$ statistics. A good fit of sudden population expansion was also observed in this haplogroup, based on sum of squared deviation values that were not significant in all the cases: demographic $(S S D=$ $0.0008, P=0.44)$ and range $(S S D=0.0008, P=0.26)$ expansion, with no significant variation of the raggedness index for both models (Table 3). In contrast, haplogroup B did not display any significant signature of expansion from the selective neutrality tests. In addition, the observed mismatch pattern for this haplogroup deviated significantly from that expected under population expansion scenario $(S S D=0.029, P=0.049$ and $P=0.011$ for demographic and spatial expansion, respectively), implying that haplogroup B did not experience any historical population expansion. This group is characterised either by a constant population size (demographic equilibrium) or had experienced a weak signal of population 
Table 4 Population genetic statistics for pairwise comparison of different populations of $R$. appendiculatus from sequences of cox 1 gene. Values in parentheses represent the $P$-value statistics

\begin{tabular}{|c|c|c|c|c|c|c|c|}
\hline \multirow[t]{2}{*}{ Population 1} & \multirow[t]{2}{*}{ Population 2} & \multicolumn{3}{|c|}{ Haplogroup A and B } & \multicolumn{3}{|l|}{ Haplogroup A } \\
\hline & & $K_{X Y}$ & $F_{S T}$ & $\mathrm{Nm}$ & $K_{X Y}$ & $F_{S T}$ & $\mathrm{Nm}$ \\
\hline DRC AEZ1 & DRC AEZ2 & $3.8(0.044)^{*}$ & $0.036(0.044)^{*}$ & 13.2 & $1.5(<0.001)^{*}$ & $0.11(<0.001)^{*}$ & 4 \\
\hline DRC AEZ1 & DRC AEZ3 & $3.6(0.032)^{*}$ & $0.057(0.032)^{*}$ & 8.3 & $1.5(0.001)^{*}$ & $0.1(0.001)^{*}$ & 4.3 \\
\hline DRC AEZ1 & Burundi AEZ1 & $3.3(0.15)$ & $0.022(0.19)$ & 22.2 & $1.2(0.31)$ & $0.002(0.33)$ & 243.6 \\
\hline DRC AEZ1 & Burundi AEZ3 & $3(0.059)$ & $0.056(0.087)$ & 8.4 & $1.3(0.087)$ & $0.043(0.082)$ & 11.2 \\
\hline DRC AEZ1 & Rwanda AEZ2 & $5.4(0.3)$ & $0.018(0.24)$ & 26.8 & $1.3(0.78)$ & $-0.026(0.79)$ & $\infty$ \\
\hline DRC AEZ2 & DRC AEZ3 & $2.7(0.85)$ & $-0.014(0.87)$ & $\infty$ & $1.4(0.93)$ & $-0.016(0.93)$ & $\infty$ \\
\hline DRC AEZ2 & Burundi AEZ1 & $2.7(0.003)^{*}$ & $0.060(0.011)^{*}$ & 7.9 & $1.5(<0.001)^{*}$ & $0.13(<0.001)^{*}$ & 3.2 \\
\hline DRC AEZ2 & Burundi AEZ3 & $2.1(0.23)$ & $0.00004(0.43)$ & 11876 & $1.3(0.46)$ & $-0.012(0.54)$ & $\infty$ \\
\hline DRC AEZ2 & Rwanda AEZ2 & $5.2(0.003)^{*}$ & $0.14(0.003)^{*}$ & 3.1 & $1.6(0.006)^{*}$ & $0.11(0.004)^{*}$ & 3.8 \\
\hline DRC AEZ3 & Burundi AEZ1 & $2.4(<0.001)^{*}$ & $0.076(0.006)^{*}$ & 6.1 & $1.5(<0.001)^{*}$ & $0.14(<0.001)^{*}$ & 3.2 \\
\hline DRC AEZ3 & Burundi AEZ3 & $1.8(0.32)$ & $-0.005(0.43)$ & $\infty$ & $1.3(0.39)$ & $-0.009(0.46)$ & $\infty$ \\
\hline DRC AEZ3 & Rwanda AEZ2 & $5.1(<0.001)^{*}$ & $0.18(<0.001)^{*}$ & 2.2 & $1.6(0.009)^{*}$ & $0.11(0.011)^{*}$ & 3.9 \\
\hline Burundi AEZ1 & Burundi AEZ3 & $1.6(0.074)$ & $0.034(0.08)$ & 12.2 & $1.2(0.077)$ & $0.063(0.073)$ & 7.4 \\
\hline Burundi AEZ1 & Rwanda AEZ2 & $4.8(0.030)^{*}$ & $0.14(0.03)^{*}$ & 3.1 & $1.2(0.97)$ & $-0.039(0.98)$ & $\infty$ \\
\hline Burundi AEZ3 & Rwanda AEZ2 & $4.6(0.005)^{*}$ & $0.19(0.005)^{*}$ & 2.1 & $1.3(0.16)$ & $0.044(0.14)$ & 10.9 \\
\hline
\end{tabular}

Abbreviations: $K_{X Y}$ average number of nucleotide differences between populations, $F_{S T}$ pairwise genetic distance $F$-statistic based on nucleotide sequences (Right's fixation index), $\mathrm{Nm}$ number of migrants between populations

*Values are statistically significant at $P<0.05$; significance was determined using 1000 coalescent simulations.

bottleneck that reduced its diversity. When analysing the demographic dynamics for samples belonging to haplogroup A in each AEZ (Table 3), population expansion signal was confirmed in all AEZs by mismatch analyses exhibiting unimodal distribution (Additional file 6: Figure S1). For the six AEZs, none of the statistical comparisons between the observed and the expected distributions rejected the sudden and range expansion assumptions based on the raggedness index and the sum of squared deviation. The neutrality indices were generally negative but not significant, except in Burundi AEZ1 where both Tajima's $D(D=-1.4, P=0.049)$ and Fu's $F s(F s=-2.6, P=0.027)$ statistics showed significant negative values and in Rwanda AEZ2 where Fu's $F s$ was negative $(F s=-2.1)$ and significant $(P=0.041)$. According to the mismatch distribution and negative values for neutrality tests, the hypothesis of population growth and spatial expansion models could not be rejected in the six AEZs, which was consistent with a model of sudden expansion for each population subdivision.

\section{Phylogeographical structure}

To study the phylogeographical structure of $R$. appendiculatus in Africa, the haplotype sequences found in this study along with those retrieved from GenBank (Additional file 1: Table S1) were used to reconstruct the phylogenetic using ML tree and the MJ network methods based on cox 1 and $12 S$ rRNA genes. Thirty-six cox 1 haplotypes were identified in 105 sequences including 50 haplotypes from GenBank and the 55 haplotype sequences obtained in our study for each of the six AEZs and for Tanzania (Table 5). Twenty-eight haplotypes had been already described in different African countries, and eight haplotypes $(\mathrm{CH} 3, \mathrm{CH}$, $\mathrm{CH} 10, \mathrm{CH} 14, \mathrm{CH} 16, \mathrm{CH} 18, \mathrm{CH} 20$ and $\mathrm{CH} 33$ ) were newly described in the present study. Most of these new haplotypes were less abundant (Additional file 3: Table S3) and diverged from the common ancestral haplotypes generally by only one substitution (Fig. 4). Haplotypes $\mathrm{CH} 1, \mathrm{CH} 7$, $\mathrm{CH} 11$ were the most ubiquitous and shared wide geographical distribution in affected African countries. CH1 haplotype was shared by Kenya, Eastern Zambia, DRC (AEZ1, 2 and 3), Burundi (AEZ1 and 3), Tanzania and Rwanda (AEZ2 and GenBank sequences), while haplotype CH7 was reported in Kenya, South Africa, Zimbabwe, Grande Comore, Eastern and southern provinces of Zambia, DRC (AEZ1, 2 and 3), Burundi (AEZ1) and Rwanda (AEZ2). Haplotype CH11 was present in Kenya, Rwanda (AEZ2 and GenBank sequences), Comoros and DRC (AEZ1, 2 and 3). Eighteen haplotypes mostly with unique sequences were found to be restricted to Kenya and have not been reported in any other country. In the same way, haplotype $\mathrm{CH} 23$ was particular to Uganda. This country did not share any haplotype with other countries. The ML phylogenetic tree reconstructed using the 105 sequences indicated that globally, the African tick R. appendiculatus is consistently clustered into two groups (haplogroups A and B) well-supported by a ML bootstrap value of $100 \%$ (Fig. 3). Our 19 haplotypes that had been described for haplogroup A (Table 2, Additional file 3: 


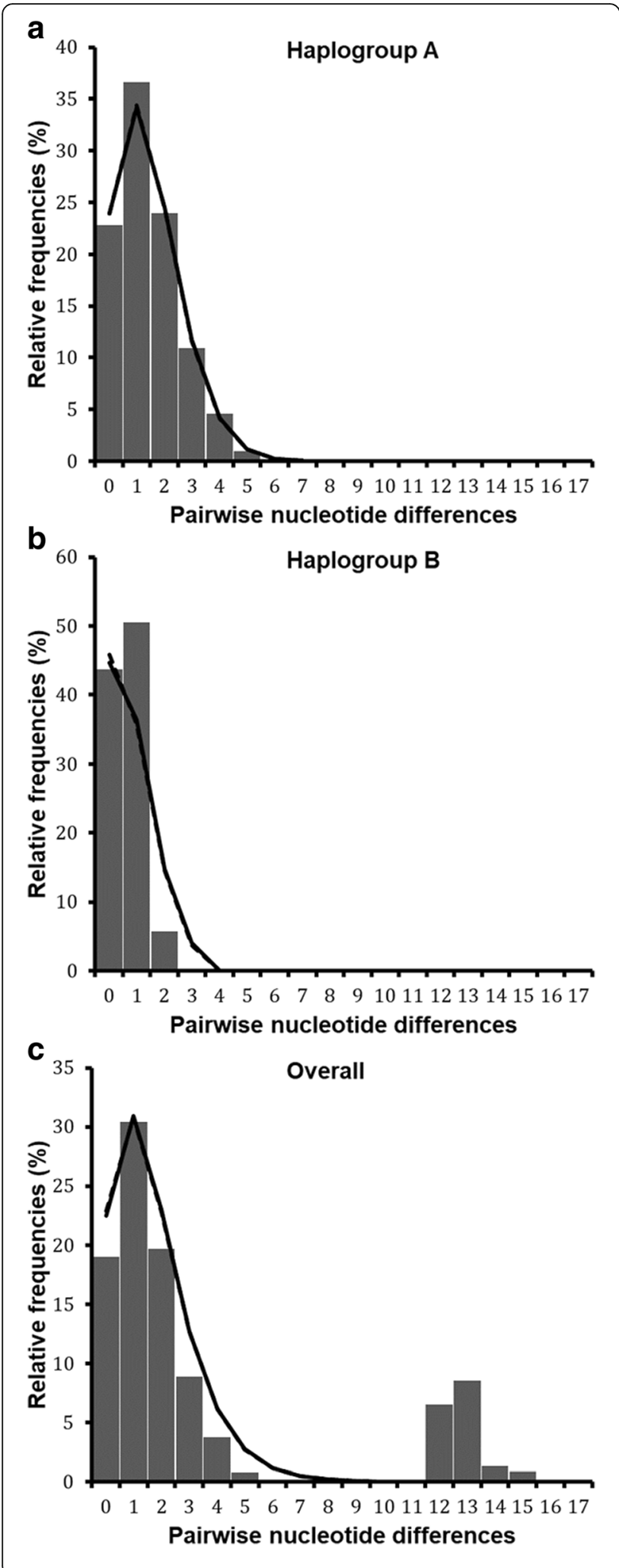

Fig. 5 cox 1 mismatch distribution pattern for two haplogroups of $R$. appendiculatus. a shows the overall mismatch distribution pattern for all AEZs, $\mathbf{b}$ and $\mathbf{c}$ show the mismatch distribution of nucleotide sequences in haplogroups $A$ and $B$, respectively. The $x$-axis shows the number of pairwise differences between pairs of haplotype sequences and the $y$-axis shows their frequencies (in \%). The observed frequencies are represented by solid histograms and the simulated mismatch distributions expected under demographic expansion (solid black line) and under spatial expansion (dotted black line). Simulated curves under range and demographic expansion have same pattern in these figures, they overlapped

Table S3) formed one clade with 19 haplotypes from Kenya (19/29), all the 3 haplotypes from Rwanda (3/3), six haplotypes from Eastern province of Zambia (6/7), all the five haplotypes from Tanzania, whereas our three haplotypes of haplogroup B were clustered with 10 haplotypes from Kenya, the single haplotype from Grande Comore, all haplotypes from South Africa (3/3), Zimbabwe (3/3), Uganda (2/2), Southern province of Zambia (2/2), and one haplotype from Eastern province of Zambia. In addition to ML tree, the MJ network also revealed that $R$. appendiculatus is divided into two main groups in Africa, separated by seven mutational steps (Fig. 4).

Similar findings were confirmed by $12 S$ rRNA gene. Our $2312 S$ rRNA individual haplotypes from each of the six AEZs were analysed together with the 29 sequences obtained from GenBank (Additional file 1: Table S1). Fourteen haplotypes were observed, two most common (12SH1 and 12SH5) and 12 minors (defined mostly by one sequence or restricted to particular country) (Additional file 7: Table S6). Haplotype 12SH1 was common in DRC, Burundi, Rwanda, Kenya and Eastern province of Zambia, while haplotype 12SH5 was present in DRC, Rwanda, Zimbabwe, Comoros, South Africa, Eastern Zambia and Kenya. Six new haplotypes were not found outside the Great lakes region (12SH3, $12 \mathrm{SH} 4$ and 12SH6-H9). The NJ phylogenetic resolved these $12 S$ rRNA haplotypes into two haplogroups (haplogroup A and B) supported by $97 \%$ bootstrap value (Additional file 8 : Figure S2). Their pattern was identical to that observed from cox1 haplogroups. However, the Ugandan haplotype (12SH10: GenBank AF150028) was clustered in haplogroup A, showing that the haplogroup A is also present in Uganda. Unfortunately, we did not find its corresponding cox 1 sequence.

\section{Discussion}

This study analysed the intraspecific variation of mitochondrial DNA to better understand how factors such as agro-ecological zones and anthropogenic movements of cattle may affect population genetic structure and population expansion history of the tick $R$. appendiculatus, the main vector of T. parva in sub-Saharan Africa. We expected evidence of $R$. appendiculatus population expansion, gene flow 

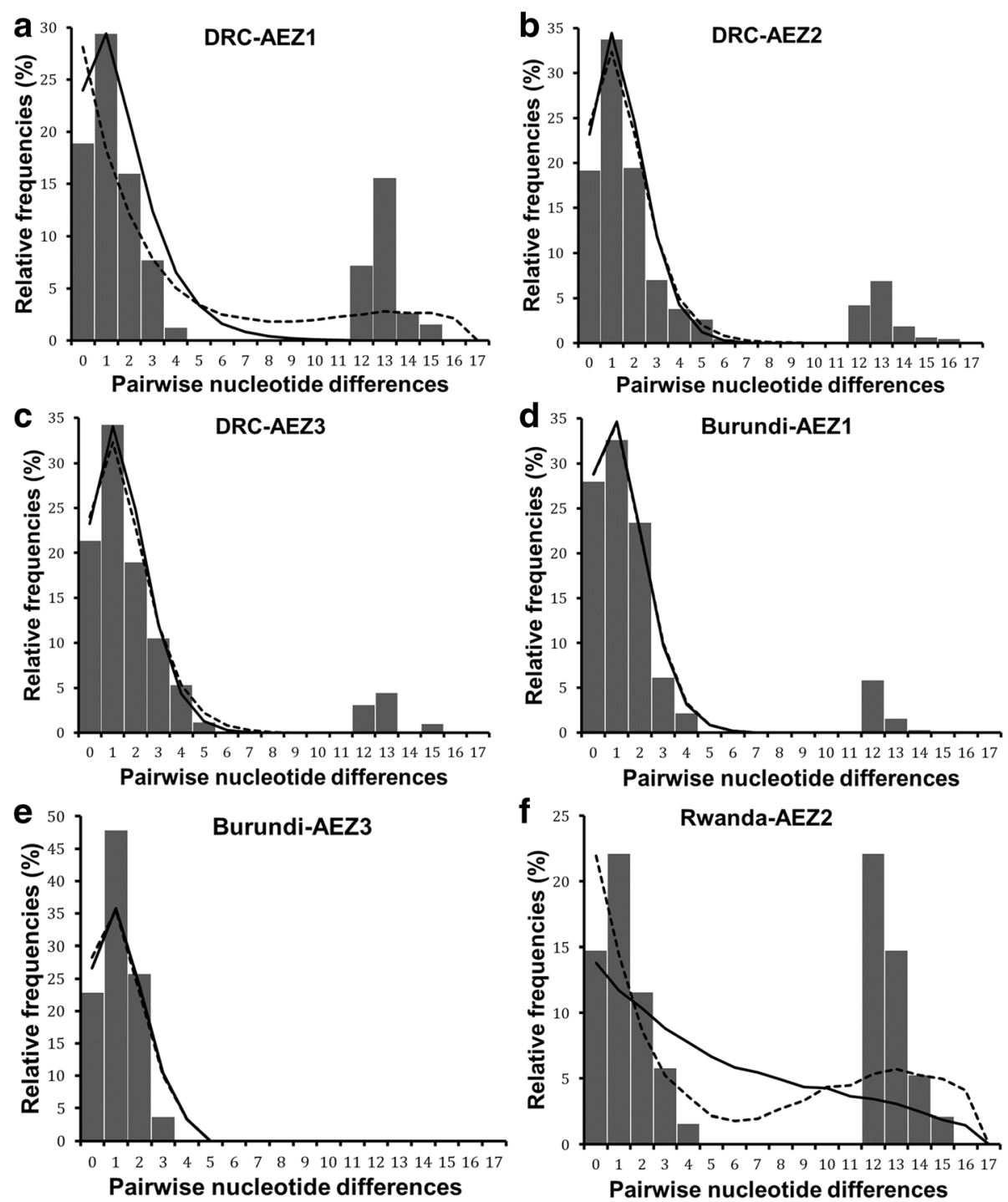

Fig. 6 cox 1 mismatch distribution pattern for six populations of $R$. appendiculatus. $\mathbf{a}, \mathbf{b}$ and $\mathbf{c}$ show the mismatch distribution pattern for $R$. appendiculatus from DRC AEZs (AEZ1, 2 and 3, respectively); $\mathbf{d}$ and e represent the mismatch pattern of ticks from Burundi AEZ1 and AEZ3, respectively; $\mathbf{f}$ depicts the mismatch distribution of ticks from Rwanda AEZ2. The $x$-axis shows the number of pairwise differences between pairs of haplotype sequences and the $y$-axis shows their frequencies in \%. The observed frequencies are represented by solid histograms. Black full line represents the expected distribution under sudden expansion model, and dotted line represents the distribution simulated under spatial expansion model. Simulated curves under spatial and demographic expansion have same pattern in (d), and they overlapped

and different colonization patterns of tick lineages, facilitated by the reported cattle mobility in the Great Lakes region.

Two $R$. appendiculatus lineages that are more variable in lowlands than highlands occur in the Great Lakes region The 22 haplotypes identified by DNA polymorphic analysis of cox 1 gene locus were clustered into two well-defined major groups, named haplogroup A (the most frequent) and haplogroup B. Similar grouping were obtained with $12 S$ rRNA analyses. The two haplogroups identified in the present study have been previously described as "east African" and "southern African" genetic groups [29], corresponding to our haplogroups A and B, respectively. This genetic grouping fitted well with the phenotypical, physiological and ecological variation studies which have previously distinguished two major subpopulations of $R$. appendiculatus in Africa [32-37, 51]. These phenotypic and physiological variations are largely associated to agro-ecological and geographical subdivisions. Tropical areas with prolonged and marked dry seasons are more suitable for larger sized ticks expressing high intensity of diapause and displaying univoltine phenology, corresponding to "southern African group" or haplogroup B. Equatorial areas with bimodal or 
Table 5 Rhipicephalus appendiculatus cox1 haplotypes and their distribution among agro-ecological zones of the Great lakes region and other sub-Saharan African countries

\begin{tabular}{|c|c|c|c|}
\hline Haplotype $^{d}$ & $\begin{array}{l}\text { Haplotypes from GenBank: Country (original haplotype name and } \\
\text { GenBank number) }\end{array}$ & Present study & Haplogroup \\
\hline $\mathrm{CH}^{\mathrm{a}}$ & 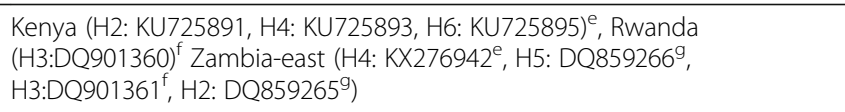 & $\begin{array}{l}\text { Burundi (AEZ1, AEZ3), DRC (AEZ1, AEZ2, AEZ3), } \\
\text { Tanzania (TZ18, TZ10, TZ08, TZ20), Rwanda } \\
\text { (AEZ2) }\end{array}$ & A \\
\hline $\mathrm{CH} 3$ & - & Burundi AEZ1 & A \\
\hline $\mathrm{CH} 4$ & Rwanda (H6: DQ901362) ${ }^{f}$ & Burundi AEZ1, Rwanda (AEZ2) & A \\
\hline $\mathrm{CH} 6^{\mathrm{b}}$ & Kenya (H5: KU725894) ${ }^{\mathrm{e}}$ & Burundi (AEZ1, AEZ3), DRC (AEZ1, AEZ2) & A \\
\hline $\mathrm{CH} 7^{\mathrm{c}}$ & 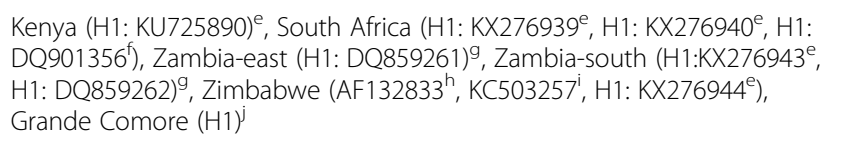 & $\begin{array}{l}\text { Burundi AEZ1, DRC (AEZ1, AEZ2, AEZ3), Rwanda } \\
\text { (AEZ2) }\end{array}$ & B \\
\hline $\mathrm{CH} 9$ & - & Burundi AEZ3 & A \\
\hline $\mathrm{CH} 10$ & - & Burundi AEZ1 & A \\
\hline $\mathrm{CH} 11^{d}$ & Kenya (H3: KU725892) ${ }^{\mathrm{e}}$, Rwanda (H3: DQ901363) ${ }^{f}$, Grande Comore $(\mathrm{H3})^{j}$ & DRC (AEZ1, AEZ2, AEZ3), Rwanda (AEZ2) & A \\
\hline $\mathrm{CH} 12$ & Kenya (H11: KU725900) $)^{e}$ & DRC (AEZ2, AEZ3) & A \\
\hline $\mathrm{CH} 14$ & - & DRC AEZ3 & A \\
\hline $\mathrm{CH} 16$ & - & DRC AEZ1 & A \\
\hline $\mathrm{CH} 18$ & - & DRC AEZ2 & A \\
\hline $\mathrm{CH} 20$ & - & DRC AEZ2 & B \\
\hline $\mathrm{CH} 23$ & Uganda (H8: KX276941, KU725897) & - & B \\
\hline $\mathrm{CH} 24$ & Kenya (H14: KU725903) & - & B \\
\hline $\mathrm{CH} 25$ & Kenya (H27: KU725916) & - & $\mathrm{B}$ \\
\hline $\mathrm{CH} 26$ & Grande Comore (H2: DQ901357) ${ }^{\mathrm{fj} j}$, Kenya (H7: KU725896, H13: KU725902) & - & B \\
\hline $\mathrm{CH} 27$ & Kenya (H16: KU725905) & - & B \\
\hline $\mathrm{CH} 28$ & Kenya (H21: KU725910 , H9: DQ901359', H9: DQ901358') & - & B \\
\hline $\mathrm{CH} 29$ & Kenya (H28: KU725917) & - & B \\
\hline $\mathrm{CH} 30$ & Kenya (H9: KU725898) & - & A \\
\hline $\mathrm{CH} 31$ & Kenya (H17: KU725906 & - & A \\
\hline $\mathrm{CH} 32$ & Kenya (H24: KU725913) & - & A \\
\hline $\mathrm{CH} 33$ & - & Tanzania (TZ13) & A \\
\hline $\mathrm{CH} 34$ & Kenya (H22: KU725911) & - & A \\
\hline $\mathrm{CH} 35$ & Kenya (H23: KU725912) & - & A \\
\hline $\mathrm{CH} 36$ & Kenya (H10: KU725899) & - & A \\
\hline $\mathrm{CH} 37$ & Kenya $(\mathrm{H} 15: \mathrm{KU} 725904)^{\mathrm{e}}$ & - & A \\
\hline $\mathrm{CH} 38$ & Kenya (H20: KU725909) ${ }^{e}$ & - & A \\
\hline $\mathrm{CH} 39$ & Kenya (H19: KU725908) & - & A \\
\hline $\mathrm{CH} 40$ & Kenya (H26: KU725915) & - & A \\
\hline $\mathrm{CH} 41$ & Kenya (H25: KU725914 & - & A \\
\hline $\mathrm{CH} 42$ & Kenya (H18: KU725907) & - & A \\
\hline $\mathrm{CH} 43$ & Kenya (H12: KU725901) & - & A \\
\hline $\mathrm{CH} 44$ & Zambia-east (H3: DQ859263) & - & A \\
\hline $\mathrm{CH} 45$ & Zambia-east (H4: DQ859264) & - & $A$ \\
\hline
\end{tabular}

${ }^{a} \mathrm{CH} 1$ : variants $\mathrm{CH} 1, \mathrm{CH} 2, \mathrm{CH} 5, \mathrm{CH} 15, \mathrm{CH} 17$ and $\mathrm{CH} 21$ (Additional file 3: Table $\mathrm{S} 3$ )

${ }^{\mathrm{b}} \mathrm{CH}$ : variants $\mathrm{CH} 6, \mathrm{CH} 8$ and $\mathrm{CH} 22$ (Additional file 3: Table S3)

${ }^{\mathrm{C}} \mathrm{CH} 7$ : variants $\mathrm{CH} 7$ and $\mathrm{CH} 13 ; \mathrm{d} \mathrm{CH} 11: \mathrm{CH} 11$ and $\mathrm{CH} 19$ (Additional file 3: Table S3)

${ }^{\mathrm{d}}$ Haplotypes underlined are exclusive to the Great Lakes region. Similar data for $12 \mathrm{~S}$ rRNA are detailed in Additional file 7: Table S6

e[31]; ${ }^{f}[29] ;{ }^{9}[52] ;{ }^{h}[68] ;{ }^{i}[69] ;{ }^{j}[14]$ 
continuous rainfall rather harbour smaller ticks without diapause with bivoltine or continuous phenology, corresponding to "east African group" or haplogroup A [37, 52].

The highest genetic variability was observed in lowlands, whereas a relatively lower diversity was observed in midlands and highlands. The high genetic diversity in lowlands can be explained by the strong presence of the two lineages A and B observed in these AEZs. The coexistence of these lineages could originate from the dispersal of the tick through livestock movement between AEZs [53], associated to the suitability of semi-arid climate for lineage B expressing obligatory diapause [37].

\section{Moderate genetic structure of $R$. appendiculatus between lowlands and highlands}

Population genetic analyses of $\operatorname{cox} 1$ gene variation in $R$. appendiculatus revealed low to moderate genetic differentiation values and high gene flow rates among AEZs. The two identified $R$. appendiculatus lineages were sympatric in the Great Lakes region, although lineage A was the most abundant and widely distributed in all AEZs and lineage B was particular confined to lowlands, where the climate is tropical dry, more arid with lower annual rainfall and longer dry season than in highlands (short dry season with abundant annual rainfall). These climate conditions in lowlands are quite similar to the described ecological zones of lineage B in southern Africa [29, 52]. In addition, altitudinal gradient seems to be a key factor that shapes the distribution pattern and the establishment ability of lineage B. Its frequency decreases with increasing altitude. High degree of genetic similarity was observed between the lowlands of DRC and the low plateau of Rwanda and between the highlands of DRC and Burundi, which are geographically distant from each other. The most likely explanation for this is that the spatial pattern of $R$. appendiculatus lineages is not only driven by geographical separation as described in previous studies [52], but also related to their ecological preferences, as observed by the significant genetic differentiation among lowlands and highlands AEZs. On the other hand, adjacent AEZs shared more migrants, especially of lineage A, facilitated by short-distance seasonal movement of cattle [9], which may have reduced the geographical structuring of the tick [11, 18]. Analysis of molecular variance (AMOVA) confirmed these findings showing that the variance explained by divergence between the six AEZs was lower $(6 \%)$, while the largest fraction of genetic variation was observed among individuals within AEZs (94\%).

\section{Rhipicephalus appendiculatus lineage $\mathrm{A}$ has undergone sudden demographic and range expansion in the Great Lakes region}

The demographic and spatial dynamics were analysed using multiple algorithms, to elucidate colonization events of the tick $R$. appendiculatus that took place in the Great Lakes region. A strong evidence of recent spatial and demographic expansion was observed for lineage $\mathrm{A}$ in all AEZs included in the study. Analyses of $\operatorname{cox} 1$ sequences revealed relatively high haplotype diversity contrasted with low nucleotide diversity values for each population, suggesting a sudden population expansion $[54,55]$. This result, together with negative values of Tajima's $D$ and Fu's $F s$, the star-like radiation, the unimodal mismatch pattern and non-significant $R I$ and $S S D$ statistics, further support the recent evolutionary history and sudden population growth experienced by lineage A [56-58]. We did not estimate the expansion time, but we hypothesize that the expansion was recent and not sufficient to increase the nucleotide diversity, probably because of recent coalescence, while rapid population expansion following a selective sweep (bottleneck or genetic drift) could have accumulated new mutations that sufficiently increased the haplotype diversity $[45$, 59, 60]. This could explain the excess of singletons polymorphic sites and rare haplotypes that diverge from ancestral haplotypes by only 1-2 mutational steps [45, 61]. However, the strong bimodal mismatch pattern observed in Rwanda AEZ2 and DRC AEZ1 suggests the coexistence of $R$. appendiculatus lineages after recent colonization events or exchanging migrants $[45,56,62]$. The scenario of lineage $B$ contrasts with that of lineage A. Analyses indicate, for lineage $B$, an equilibrium situation that is characterised by a weak signal of recent bottleneck and no evidence of population expansion. It was also less diverse than haplogroup A, indicating that haplogroup A is experiencing population expansion independently of haplogroup B and it has been established longer in the Great Lakes region, while haplogroup B was probably introduced more recently and established a founder population. There are three possible explanations of the equilibrium observed in haplogroup B: (i) only few haplotypes were recently introduced; (ii) only the few identified haplotypes persisted after a bottleneck; or (iii) haplogroup B is experiencing an initial selection sweep which has reduced the number of rare haplotypes and singleton mutations [56]. When we analysed $R$. appendiculatus cox 1 sequences available in Africa, the star radiation of the $\mathrm{MJ}$ network in each group suggests that the two lineages went through a demographic expansion and evolve independently of each other with limited gene exchange. Unfortunately, we were not able to test the hypothesis of crossbreeding events between the two lineages described here, because of the maternal inheritance of mitochondrial genes used in the present study. More studies, such as extensive biological characterisation, crossbreeding experiments and the use of biparental inheritance markers are necessary to investigate the panmixia of the two lineages and the genetic mechanisms driving their establishment and corresponding phenotypic variations in changed environments. 
The fact that $R$. appendiculatus has undergone spatial expansion was in accordance with the expectation that long and short distance movement of cattle are key factors of spreading ticks. The processes responsible for that evolutionary pattern may have resulted, not only from range expanding of the previously established haplotypes to proximate AEZs, but also from the recolonization events of ticks from other regions and countries [53, 63]. In addition to cattle movement, the population expansion and establishment of novel haplotypes in previously unoccupied areas could have been driven by recent environmental and climatic changes, affecting vector-borne diseases landscape over recent decades [64-66].

\section{Sympatric and allopatric ecological zones of $R$. appendiculatus lineages in Africa}

Phylogenetic trees produced two main genetic subpopulations of $R$. appendiculatus that have a wide distribution range in Africa, with large divergence in behavioural diapause [36, 37], spatial variation in body size [35, 51], ecology and phenology [32-34]. Initially, the two lineages were considered as "east African" and "southern African" genetic groups [29]. To date, they are sympatric in most eastern and central African ecological zones. For instance, previous studies did not reveal the presence of haplogroup B in Rwanda [29]. This could be an indication of recent introduction of the tick in the Great Lakes region. The MJ network further elucidate that the initial population of haplogroup B could have come from an ancestral female of haplotype $\mathrm{CH} 7$, which is the most prevalent haplotype of this group in areas where it occurs. Consequently, two different eco-genetic zones are shaped in Africa, the sympatric zone where the two lineages are found, which covers central and eastern Africa, and allopatric zone in southern Africa where the two lineages have clear geographical and ecological separation. For instance, in Zambia, lineage B is present in the south (long dry season) and lineage A in the east of the country (shorter dry season) [29]. In Grande Comore, lineage $\mathrm{B}$ has established a stable population, while lineage A was found on imported cattle [14]. In areas where the two lineages are sympatric, their respective abundances differ, mainly driven by their divergence in ecological preferences and plasticity [33]. The sympatric relationship is in agreement with the observation made by Berkvens et al. [67], where an east African stock from Kenya expressed diapause, contrasting with the result obtained by Madder et al. [36], where another stock from the same region was unable to enter diapause. These evidences show that lineage $\mathrm{B}$ has a greater invasive ability into new habitats and better fit wide range of tropical and equatorial conditions, while lineage $\mathrm{A}$ is particularly confined to equatorial conditions. This could be explained by the larger body size and obligatory diapause behaviour for southern African ticks, which allow them to survive hot and dry ecological conditions [33, 37]. We hypothesise that these characteristics make the development of lineage B slower than lineage A in sympatric areas, giving an evolutionary advantage to the latter. This could also reduce the abundance of lineage B delaying its oviposition during unfavourable conditions [37]. The processes that took place to divide the two groups need to be further investigated. However, we propose that they could have diverged following genetic drift due to founder events of natural geographical barrier that may result in reproductive isolation. It is demonstrated that biogeographical break again host migration reduces gene exchange and could dictate the spatial and reproductive separation within a species [60].

\section{Conclusions}

This study provided new insights into the genetic structure and colonization events of $R$. appendiculatus in the Great Lakes region and over its distribution range in sub-Saharan Africa. Our results highlighted the occurrence of two major genetic lineages (A and B) in the Great Lakes region. The two lineages are not spatially structured in the study region and they differ in their colonization histories and pattern. Lineage B, not previously reported, was probably introduced recently in the region and its occurrence decreases with increased altitude, whereas lineage A, widely distributed, has been longer established and subjected to sudden demographic and spatial expansion most likely related to short and long-distance cattle movement. Rhipicephalus appendiculatus ticks are more diverse in lowlands than highlands with moderate genetic differentiation between the two ecosystems, while more genetic similitude is found in zones with same agro-ecological profiles, in spite of their geographical distance. The genetic distribution of $R$. appendiculatus suggests two different eco-genetic zones in Africa, the sympatric zone (central and eastern Africa) where the two lineages coexist and the allopatric zones (southern Africa) where they have clear geographical divergence. The range expansion pattern of lineages and the genetic admixture of $R$. appendiculatus populations observed in the Great Lakes region can strongly affect the epidemiological dynamics of ECF. This could partially explain the endemic instability and occasional epidemics due to the introduction and temporal subsistence of infected ticks mostly in fringes areas of lowlands.

\section{Additional files}

Additional file 1: Table S1. Rhipicephalus appendiculatus cox 1 and 125 rRNA haplotype sequences retrieved from GenBank. (DOCX 16 kb)

Additional file 2: Table S2. Cox 1 and 125 rRNA BLAST results for species identification and confirmation. (DOCX 16 kb) 
Additional file 3: Table S3. Polymorphism in the 22 haplotypes of the cox1 gene fragment of $R$. appendiculatus. (DOCX $21 \mathrm{~kb}$ )

Additional file 4: Table S4. Population genetic structure inferred by analysis of molecular variance (AMOVA) based on cox1 sequences of $R$. appendiculatus from different agro-ecological zones. (DOCX $13 \mathrm{~kb}$ )

Additional file 5: Table S5. Evolutionary neutrality, demographic and spatial history of mitochondrial cox1 gene. (DOCX $15 \mathrm{~kb}$ )

Additional file 6: Figure S1. cox1 mismatch distribution pattern for $R$. appendiculatus haplogroup A in different agro-ecological zones. (DOCX 193 kb)

Additional file 7: Table S6. Rhipicephalus appendiculatus 125 rRNA haplotypes and their distribution among agro-ecological zones of the Great lakes region and other sub-Saharan African countries. (DOCX $15 \mathrm{~kb}$ )

Additional file 8: Figure S2. Neighbor-joining tree of 125 haplotype sequences for $R$. appendiculatus across African countries. (DOCX $18 \mathrm{~kb}$ )

\section{Abbreviations}

AMOVA: Analysis of molecular variance; BecA: Biosciences eastern and central Africa; BLAST: Basic local alignment search tool; cox1: Cytochrome $c$ oxidase subunit 1; D: Tajima's neutrality test; ECF: East Coast fever; Fs: Fu's neutrality tests; $F_{S T}$ : Right's fixation index; $h$ : Number of haplotypes; $H d$ : Haplotype diversity; ILRI: International Livestock Research Institute; ITS2: Internal transcribed spacer 2; K: Mean number of pairwise nucleotide differences within population; $K_{x y}$ : Average number of nucleotide differences between populations; ML: Maximum likelihood; NCBI: National Center for Biotechnology Information; NJ: Neighbor-joining; Nm: Number of migrants; PCR: Polymerase chain reaction; PIS: Parsimony informative sites; RI: Harpending's raggedness index; rRNA: ribosomal RNA; S: Segregating sites; SD: Standard deviation; SSD: Sum of squares deviation; $\pi$ : nucleotide diversity

\section{Acknowledgments}

We would like to thank Professor Paul Gwakisa from the Sokoine University of Agriculture (SUA) in Tanzania for providing tick specimens from Tanzania. We thank Alphone Bisusa from the Centre de Recherche en Sciences Naturelles (CRSN/Lwiro) and Amzati Saidi Ngton (Université Evangélique en Afrique) for technical assistance with sample collection and tick identification. We are also grateful to the technical staff of BecA-ILRI for facilitating laboratory work, especially Stephen Mwaura (tick unit-ILRI) for assistance with the confirmation of morphological identification of closely related tick species. We thank Dr Marie Cariou (Research Unit in Environmental and Evolutionary Biology, University of Namur) for advising on data analysis and interpretation. We are also grateful to Professor Gustave Mushagalusa (Université Evangélique en Afrique) for mobilizing partnerships and collaborations to the "Theileria" project in DRC.

\section{Funding}

The laboratory aspects of this project were fully supported by the BecA-ILR Hub through the Africa Biosciences Challenge Fund (ABCF) program. The ABCF Program is funded by the Australian Department for Foreign Affairs and Trade (DFAT) through the BecA-CSIRO partnership; the Syngenta Foundation for Sustainable Agriculture (SFSA); the Bill \& Melinda Gates Foundation (BMGF); the UK Department for International Development (DFID) and; the Swedish International Development Cooperation Agency (Sida). Sample collection, field equipment and scientific workshop organised in DRC were supported through the "Theileria" project co-funded to the Université Evangélique en Afrique (UEA) by the Agence Universitaire de la Francophonie (AUF) and the Communauté Economique des Pays des Grands Lacs (CEPGL). The International foundation of Science (IFS) supported in collaboration with BecA-ILRI hub the individual scholarship awarded to GSA for field work and part of field equipment to the "Theileria" project. The study was also supported by the University of Namur through the UNamur-CERUNA institutional PhD grant awarded to GSA for manuscript write-up in Belgium.

\section{Availability of data and materials}

The data supporting the findings of this study are included within the article and its additional files. Representative sequences of $R$. appendiculatus from each agro-ecological zone (AEZ) are available in the GenBank database under accession numbers: MF458895-MF458949 and MF479166-MF479188 for cox1 and 125 rRNA genes, respectively. The 22 cox 1 haplotypes were submitted to
GenBank under accession numbers MF458950-MF458971 and the GenBank numbers for the nine 12S rRNA haplotypes are MF479189-MF479197.

\section{Authors' contributions}

GSA collected and identified ticks, performed experiments, analysed data and wrote the manuscript. TM, NK and GSA conceived the study. TM, NK, RP $J B M, A D$ and $M M$ participated in the study design, supervised the research and critically revised the manuscript. RP and EGK participated in laboratory experiments and advised in data analyses. JBM supervised tick collections. All authors read and approved the final manuscript.

\section{Ethics approval and consent to participate}

The research was carried out in accordance with ethical guidelines and regulations of the Université Evangélique en Afrique (UEA/Bukavu-DR Congo). The specific field protocols were approved by the UEA (Reference number: UEA/SGAC/KM/020/2015) and permitted by the Provincial Inspection of Agriculture, Livestock and Fisheries (Reference number: 55.00/ 0026/IPAPEL/SK/2015). Farm managers and owners were informed about the survey and gave approval for tick collection on their cattle. This research did not involve species at risk of extinction.

\section{Competing interests}

The authors declare that they have no competing interests.

\section{Publisher's Note}

Springer Nature remains neutral with regard to jurisdictional claims in published maps and institutional affiliations.

\section{Author details}

${ }^{1}$ Unit of Integrated Veterinary Research, Department of Veterinary Medicine, Faculty of Sciences, Namur Research Institute for Life Sciences (NARILIS), University of Namur (UNamur), Rue de Bruxelles 61, 5000 Namur, Belgium. ${ }^{2}$ Research Unit of Veterinary Epidemiology and Biostatistics, Faculty of Agricultural and Environmental Sciences, Université Evangélique en Afrique, P.O. Box 3323, Bukavu, Democratic Republic of the Congo. ${ }^{3}$ Biosciences eastern and central Africa - International Livestock Research Institute (BecA-ILRI) hub, P.O. Box 30709-00100, Nairobi, Kenya. ${ }^{4}$ Department of Biochemistry, School of Medicine, University of Nairobi, P.O. Box 30197-00100, Nairobi, Kenya. ${ }^{5}$ Present address: Centre for Tropical Livestock Genetics and Health (CTLGH), The University of Edinburgh, Easter Bush, Midlothian, Scotland EH25 9RG, UK. ${ }^{6}$ Department of Veterinary Tropical Diseases, Faculty of Veterinary Science, University of Pretoria, P/Bag X04, Onderstepoort 0110, South Africa.

Received: 11 January 2018 Accepted: 16 May 2018

Published online: 31 May 2018

\section{References}

1. Nene V, Kiara H, Lacasta A, Pelle R, Svitek N, Steinaa L. The biology of Theileria parva and control of East Coast fever - Current status and future trends. Ticks Tick Borne Dis. 2016;7:549-64.

2. Kalume MK, Saegerman C, Mbahikyavolo DK, Makumyaviri AM, Marcotty T, Madder M, et al. Identification of hard ticks (Acari: Ixodidae) and seroprevalence to Theileria parva in cattle raised in North Kivu Province, Democratic Republic of Congo. Parasitol Res. 2013;112:789-97.

3. Bazarusanga T, Geysen D, Vercruysse J, Madder M. An update on the ecological distribution of ixodid ticks infesting cattle in Rwanda: countrywide cross-sectional survey in the wet and the dry season. Exp Appl Acarol. 2007:43:279-91.

4. Kaiser M, Sutherst R, Bourne A, Gorissen L, Floyd R. Population dynamics of ticks on Ankole cattle in five ecological zones in Burundi and strategies for their control. Prev Vet Med. 1988;6:199-222.

5. Olwoch J, Reyers B, van Jaarsveld A. Host-parasite distribution patterns under simulated climate: implications for tick-borne diseases. Int I Climatol. 2009;29:993-1000

6. Perry B, Lessard P, Norval R, Kundert K, Kruska R. Climate, vegetation and the distribution of Rhipicephalus appendiculatus in Africa. Parasitol Today. 1990;6:100-4.

7. Mararo SB. Pouvoirs, élevage bovin et la question foncière au Nord-Kivu. In: Marysse S, Reyntjens F, editors. L'Afrique des Grands Lacs: annuaire 20002001. Paris: L'Harmattan; 2001. p. 219-50. 
8. De Failly D. L'économie du Sud-Kivu 1990-2000: mutations profondes cachées par une panne. In: Marysse S, Reyntjens F, editors. L'Afrique des Grands Lacs: annuaire 1999-2000. Paris: L'Harmattan; 2000. p. 163-92.

9. Verweijen J, Brabant J. Cows and guns. Cattle-related conflict and armed violence in Fizi and Itombwe, eastern DR Congo. J Mod Afr Stud. 2017;55:1-27.

10. Vlassenroot $K$, Huggins C. Land, migration and conflict in eastern DRC. In: Huggins C, Clover J, editors. From the ground up: land rights, conflict and peace in sub-Saharan Africa. Pretoria: Institute for Security Studies; 2005. p. 115-94.

11. Boulinier T, Kada S, Ponchon A, Dupraz M, Dietrich M, Gamble A, et al. Migration, prospecting, dispersal? What host movement matters for infectious agent circulation? Integr Comp Biol. 2016;56:330-42.

12. Maze-Guilmo E, Blanchet S, McCoy KD, Loot G. Host dispersal as the driver of parasite genetic structure: a paradigm lost? Ecol Lett. 2016;19:336-47.

13. De Deken R, Martin V, Saido A, Madder M, Brandt J, Geysen D. An outbreak of East Coast fever on the Comoros: a consequence of the import of immunised cattle from Tanzania? Vet Parasitol. 2007:143:245-53.

14. Yssouf A, Lagadec E, Bakari A, Foray C, Stachurski F, Cardinale E, et al. Colonization of Grande Comore Island by a lineage of Rhipicephalus appendiculatus ticks. Parasit Vectors. 2011;4:38.

15. Fevre EM, Bronsvoort BM, Hamilton KA, Cleaveland S. Animal movements and the spread of infectious diseases. Trends Microbiol. 2006;14:125-31.

16. Barre N, Uilenberg G. Spread of parasites transported with their hosts: case study of two species of cattle tick. Rev Sci Tech. 2010;29:135-47.

17. Estrada-Peña A, Salman M. Current limitations in the control and spread of ticks that affect livestock: a review. Agriculture. 2013;3:221-35.

18. Leo SS, Gonzalez A, Millien V. The genetic signature of range expansion in a disease vector-the black-legged tick. J Hered. 2017;108:176-83.

19. Ogden N. Changing geographic ranges of ticks and tick-borne pathogens: drivers, mechanisms and consequences for pathogen diversity. Front Cell Infect Microbiol. 2013;3:46.

20. Criscione CD, Poulin R, Blouin MS. Molecular ecology of parasites: elucidating ecological and microevolutionary processes. Mol Ecol. 2005;14:2247-57.

21. Gooding RH. Genetic variation in arthropod vectors of disease-causing organisms: obstacles and opportunities. Clin Microbiol Rev. 1996;9:301-20.

22. Gandon S, Michalakis Y. Local adaptation, evolutionary potential and hostparasite coevolution: interactions between migration, mutation, population size and generation time. J Evol Biol. 2002;15:451-62.

23. Kubasu S. The ability of Rhipicephalus appendiculatus (Acarina: Ixodidae) stocks in Kenya to become infected with Theileria parva. Bull Entomol Res. 1992;82:349-53.

24. Odongo DO, Ueti MW, Mwaura SN, Knowles DP, Bishop RP, Scoles GA Quantification of Theileria parva in Rhipicephalus appendiculatus (Acari: Ixodidae) confirms differences in infection between selected tick strains. J Med Entomol. 2009;46:888-94.

25. Young AS, Dolan TT, Mwakima FN, Ochanda H, Mwaura SN, Njihia GM, et al. Estimation of heritability of susceptibility to infection with Theileria parva in the tick Rhipicephalus appendiculatus. Parasitology. 1995;111:31-8.

26. Ochanda $H$, Young A, Medley G, Perry B. Vector competence of 7 rhipicephalid tick stocks in transmitting 2 Theileria parva parasite stocks from Kenya and Zimbabwe. Parasitology. 1998;116:539-45.

27. McCoy K. The population genetic structure of vectors and our understanding of disease epidemiology. Parasite. 2008;15:444-8.

28. Le Roux J, Wieczorek A. Molecular systematics and population genetics of biological invasions: towards a better understanding of invasive species management. Ann Appl Biol. 2009;154:1-7.

29. Mtambo J, Madder M, Van Bortel W, Geysen D, Berkvens D, Backeljau T. Genetic variation in Rhipicephalus appendiculatus (Acari: Ixodidae) from Zambia: correlating genetic and ecological variation with Rhipicephalus appendiculatus from eastern and southern Africa. J Vector Ecol. 2007;32:168-75.

30. Kanduma EG, Mwacharo JM, Mwaura S, Njuguna JN, Nzuki I, Kinyanjui PW, et al. Multi-locus genotyping reveals absence of genetic structure in field populations of the brown ear tick (Rhipicephalus appendiculatus) in Kenya. Ticks Tick Borne Dis. 2016;7:26-35.

31. Kanduma EG, Mwacharo JM, Githaka NW, Kinyanjui PW, Njuguna JN, Kamau LM, et al. Analyses of mitochondrial genes reveal two sympatric but genetically divergent lineages of Rhipicephalus appendiculatus in Kenya. Parasit Vectors. 2016;9:353.

32. Berkvens DL, Geysen DM, Chaka G, Madder M, Brandt JR. A survey of the ixodid ticks parasitising cattle in the Eastern Province of Zambia. Med Vet Entomol. 1998;12:234-40.
33. Speybroeck N, Madder M, Van Den Bossche P, Mtambo J, Berkvens N, Chaka $\mathrm{G}$, et al. Distribution and phenology of ixodid ticks in southern Zambia. Med Vet Entomol. 2002;16:430-41.

34. Leta S, De Clercq EM, Madder M. High-resolution predictive mapping for Rhipicephalus appendiculatus (Acari: Ixodidae) in the Horn of Africa. Exp Appl Acarol. 2013;60:531-42.

35. Chaka G, Billiouw M, Geysen DM, Berkvens DL. Spatial and temporal variation in Rhipicephalus appendiculatus size in eastern Zambia. Trop Med int Health. 1999;4:A43-8.

36. Madder M, Speybroeck N, Brandt J, Berkvens D. Diapause induction in adults of three Rhipicephalus appendiculatus stocks. Exp Appl Acarol. 1999; 23:961-8.

37. Madder M, Speybroeck N, Brandt J, Tirry L, Hodek I, Berkvens D. Geographic variation in diapause response of adult Rhipicephalus appendiculatus ticks. Exp Appl Acarol. 2002;27:209-21.

38. Bazarusanga T, Vercruysse J, Marcotty T, Geysen D. Epidemiological studies on theileriosis and the dynamics of Theileria parva infections in Rwanda. Vet Parasitol. 2007;143:214-21.

39. Walker AR, Bouattour A, Camicas J-L, Estrada-Pena A, Horak IG, Latif AA, et al. Ticks of domestic animals in Africa: a guide to identification of species. Edinburgh, Scotland: Bioscience Reports; 2003.

40. Folmer O, Black M, Hoeh W, Lutz R, Vrijenhoek R. DNA primers for amplification of mitochondrial cytochrome c oxidase subunit I from diverse metazoan invertebrates. Mol Mar Biol Biotechnol. 1994;3:294-9.

41. Simon C, Frati F, Beckenbach A, Crespi B, Liu H, Flook P. Evolution, weighting, and phylogenetic utility of mitochondrial gene sequences and a compilation of conserved polymerase chain reaction primers. Ann Entomol Soc Am. 1994;87:651-701.

42. Librado P, Rozas J. DnaSP v5: a software for comprehensive analysis of DNA polymorphism data. Bioinformatics. 2009:25:1451-2.

43. Excoffier $L$, Lischer HE. Arlequin suite ver 3.5: a new series of programs to perform population genetics analyses under Linux and Windows. Mol Ecol Resour. 2010;10:564-7.

44. Meirmans PG, Hedrick PW. Assessing population structure: FST and related measures. Mol Ecol Resour. 2011;11:5-18.

45. Rogers AR, Harpending $H$. Population growth makes waves in the distribution of pairwise genetic differences. Mol Biol Evol. 1992;9:552-69.

46. Harpending HC. Signature of ancient population growth in a low-resolution mitochondrial DNA mismatch distribution. Hum Biol. 1994;66:591-600.

47. Fu YX. Statistical tests of neutrality of mutations against population growth, hitchhiking and background selection. Genetics. 1997;147:915-25.

48. Tajima F. Statistical method for testing the neutral mutation hypothesis by DNA polymorphism. Genetics. 1989;123:585-95.

49. Kumar S, Stecher G, Tamura K. MEGA7: Molecular Evolutionary Genetics Analysis Version 7.0 for bigger datasets. Mol Biol Evol. 2016;33:1870-4.

50. Leigh JW, Bryant D. popart: full-feature software for haplotype network construction. Methods Ecol Evol. 2015:6:1110-6.

51. Speybroeck N, Madder M, Thulke HH, Mtambo J, Tirry L, Chaka G, et al. Variation in body size in the tick complex Rhipicephalus appendiculatus/ Rhipicephalus zambeziensis. J Vector Ecol. 2004;29:347-54

52. Mtambo J, Madder M, Van Bortel W, Chaka G, Berkvens D, Backeljau T. Further evidence for geographic differentiation in $R$. appendiculatus (Acari: xodidae) from Eastern and Southern provinces of Zambia. Exp Appl Acarol. 2007:41:129-38.

53. Excoffier L, Foll M, Petit RJ. Genetic consequences of range expansions. Annu Rev Ecol Evol Syst. 2009:40:481-501.

54. Braverman JM, Hudson RR, Kaplan NL, Langley CH, Stephan W. The hitchhiking effect on the site frequency spectrum of DNA polymorphisms. Genetics. 1995;140:783-96.

55. Simonsen KL, Churchill GA, Aquadro CF. Properties of statistical tests of neutrality for DNA polymorphism data. Genetics. 1995;141:413-29.

56. Ray N, Currat M, Excoffier L. Intra-deme molecular diversity in spatially expanding populations. Mol Biol Evol. 2003;20:76-86

57. Frankham R. Relationship of genetic variation to population size in wildlife Conserv Biol. 1996;10:1500-8.

58. Emerson BC, Paradis E, Thébaud C. Revealing the demographic histories of species using DNA sequences. Trends Ecol Evol. 2001;16:707-16.

59. Robbertse L, Baron S, van der Merwe NA, Madder M, Stoltsz WH, MaritzOlivier C. Genetic diversity, acaricide resistance status and evolutionary potential of a Rhipicephalus microplus population from a disease-controlled cattle farming area in South Africa. Ticks Tick Borne Dis. 2016;7:595-603. 
60. Avise JC. Phylogeography: The history and formation of species. USA: Harvard University Press; 2000.

61. Slatkin M, Hudson RR. Pairwise comparisons of mitochondrial DNA sequences in stable and exponentially growing populations. Genetics. 1991; 129:555-62.

62. Rogers AR, Fraley AE, Bamshad MJ, Watkins WS, Jorde LB. Mitochondrial mismatch analysis is insensitive to the mutational process. Mol Biol Evol. 1996;13:895-902

63. Cristescu ME. Genetic reconstructions of invasion history. Mol Ecol. 2015;24:2212-25.

64. Biek R, Real LA. The landscape genetics of infectious disease emergence and spread. Mol Ecol. 2010;19:3515-31.

65. Ostfeld RS. Climate change and the distribution and intensity of infectious diseases. Ecology. 2009;90:903-5.

66. Manel S, Holderegger R. Ten years of landscape genetics. Trends Ecol Evol. 2013;28:614-21.

67. Berkvens DL, Pegram RG, Brandt JR. A study of the diapausing behaviour of Rhipicephalus appendiculatus and R. zambeziensis under quasi-natural conditions in Zambia. Med Vet Entomol. 1995;9:307-15.

68. Murrell A, Campbell NJH, Barker SC. Phylogenetic analyses of the rhipicephaline ticks indicate that the genus Rhipicephalus is paraphyletic. Mol Phylogenet Evol. 2000;16:1-7.

69. Burger TD, Shao R, Barker SC. Phylogenetic analysis of mitochondrial genome sequences indicates that the cattle tick, Rhipicephalus (Boophilus) microplus, contains a cryptic species. Mol Phylogenet Evol. 2014;76:241-53.

Ready to submit your research? Choose BMC and benefit from:

- fast, convenient online submission

- thorough peer review by experienced researchers in your field

- rapid publication on acceptance

- support for research data, including large and complex data types

- gold Open Access which fosters wider collaboration and increased citations

- maximum visibility for your research: over $100 \mathrm{M}$ website views per year

At BMC, research is always in progress.

Learn more biomedcentral.com/submissions 